Part A

Manuscript Number: JCOMA-18-1563R1

Title: Sorption behaviour of bamboo fibre reinforced composites, why do they retain their properties?

Article Type: Research Paper

Keywords: A. Biocomposite; B. Mechanical properties; C. Damage mechanics; D. Moisture

Corresponding Author: Miss Delphine E. C. Depuydt,

Corresponding Author's Institution: KU Leuven Department of Materials Engineering, Campus Groep T, Andreas Vesaliusstraat 13, 3000 Leuven, Belgium

First Author: Delphine E. C. Depuydt

Order of Authors: Delphine E. C. Depuydt; Jeroen Soete; Yalew D Asfaw; Martine Wevers; Jan Ivens; Aart W van Vuure

Abstract: The influence of moisture on the mechanical properties of bamboo fibre reinforced composites was assessed both for static and hygroscopic cyclic conditioning. Static conditioning revealed that bamboo fibre reinforced composites show a smaller decrease in Young's modulus with moisture content than other natural fibre reinforced composites such as for example flax based composites. The behaviour is explained by the chemical composition of the fibre and demonstrated by dynamic mechanical analysis that illustrates how composites made with fibres of high lignin content retain their glass transition temperature in moist conditions. The influence of hygroscopic cycling was also assessed, with emphasis on the influence of the remaining parenchyma on the fibre surface. Clean fibres, are beneficial for the long term behaviour, with less deterioration in properties. Porosity analysis was performed via X-ray computed tomography to provide insight into the material structure of the composite and the effects of hygroscopic cycling.

Response to Reviewers: Ms. Ref. No.: JCOMA-18-1563

Title: Sorption behaviour of bamboo fibre reinforced composites, why do they retain their properties?

Composites Part A

Dear Depuydt,

The referees have now completed reviewing your paper and their comments are given below. The paper is recommended to be accepted only after mandatory revisions. Before we can proceed, please let me have a pointby-point response to the issues raised in the reviews together with a revised version of the paper. A final decision will be made after receiving the revised version and your response.

Please clearly indicate where changes have been made, for example by using a different colour. If you are using MS Word, you can highlight 
changes using the "Track Changes" feature. In 'Tools', choose 'Track Changes', 'Highlight Changes' and tick 'Track changes while editing'.

Please note that, according to journal guidelines, revisions should be submitted within 30 days.

To submit a revision, please go to https://ees.elsevier.com/compositesa/ and login as an Author.

Your username is: delphine.depuydt@kuleuven.be

If you need to retrieve password details, please go to: http://ees.elsevier.com/compositesa/automail_query.asp

On your Main Menu page is a folder entitled "Submissions Needing Revision". You will find your submission record there.

Composites Part A features the Interactive Plot Viewer, see: http://www.elsevier.com/interactiveplots. Interactive Plots provide easy access to the data behind plots. To include one with your article, please prepare a .cSv file with your plot data and test it online at http://authortools.elsevier.com/interactiveplots/verification before submission as supplementary material.

With many thanks,

Kristiina Oksman, Ph.D.

Biocomposites editor

Composites Part A

Editor/referees' comments:

If the reviewer has uploaded his comments as an attachment you will need to login to your author main menu to download the attached file.

The authors would like to thank the editor and the reviewers for the time they've put in reviewing this manuscript. We believe the suggestions and comments helped to improve the text significantly.

Kind regards,

The authors

Reviewer \#1: Manuscript $n^{\circ}$ JCOMA-18-1563 entitled "Sorption behaviour of bamboo fibre reinforced composites, why do they retain their properties?" Although the topic is very interesting and deserves research to be focused on, the structure of the article is confusing and the quality of the results and interpretation are not sufficient to be published in comp part A.

Introduction :

L5-p2 You mean that all natural fibres can compete with glass but it is not strictly right, bast fibres can but fruits fibres cannot.

This point has been added, it has been made clear that it mainly counts for bast and grass fibres.

L6-p2 Environmental benefit is cited for natural fibres and their composites, please cite original research articles

References have been added 
L22p2 Moisture induced degradations are cited, please cite original research articles

References have been added

L52p2 "reduce" rather than "destroy"

This has been changed

L1p3 Please mention that table 1 is dedicated to natural fibre reinforced thermoset polymer

This has been added

L43p3 The review of the literature highlighting moisture induced

degradation is interesting but is lacking from information dedicated to the relation between the biochemical composition of the fibre and the polysaccharide leashing. Two articles in the literature are available and have shown that leashing, depending on the fibre biochemistry is a drastic degradation scenario for natural fibres (This is exactly the topic of your article):

Please See :

*A le Duigou, A Bourmaud, and C Baley, In-situ evaluation of flax fibre degradation after water aging, Industrial Crops and Products, 2015, 70, $204-210$

*A Le Duigou, S Requile, J Beaugrand, F Scarpa and M Castro, Natural fibres actuators for smart bio-inspired hygromorph biocomposites, smart Materials and Structures, 2017, 26, 12

The first paper referred to, studies the evolution of the mechanical properties of flax fibres (by nanoindentation) after the immersion of the composites. Nanoindentation was performed after drying of the samples, and a decrease in mechanical properties was found, which was linked to the leaching of polysaccharides, which lowered the load transfer between the microfibrils, resulting in lower properties. This research is very interesting, however, the proposed manuscript focuses on bamboo fibres, which differ in chemical composition from flax fibres, more specific, they contain almost no pectins. Chemical characterisation of bamboo in other (not yet published work) reveals a cellulose content of 55\%, hemicellulose $14 \%$ and lignin $31 \%$ and $0.7 \mathrm{~g} / 100 \mathrm{~g}$ extractives (in neutral detergent solvent), this comprises soluble carbohydrates, lipids and proteins. For this reason leaching is far less important when it comes to bamboo fibres. Also, in this work the mechanical performance of bamboo and flax is compared in the moisture saturated phase in a humid environment, exposed to gaseous water, not liquid. No immersion is applied, and therefore leaching can only be minor, and cannot explain the difference in mechanical properties. For completeness of the manuscript the leaching phenomenon has been added to the text.

L1p5 You are talking about cellulose, hemicellulose and lignin... but what about pectins? Their presence has a great role especially for flax (in middle lamellae, primary and secondary cell wall) and they are very sensitive to moisture. Please add information

The information about the change in glass transition temperature referred to in this paper is based on the available measurements for wood, comprising the data on the main constituents of wood. Pectin is not one of them, and no information is available on that. Bamboo is very similar to wood, regarding its chemical composition, therefore this wood reference is very relevant. Information on the glass transition temperature of pectin in dry and wet condition is not available to the best of the authors' knowledge. Based on the structure of pectin, one might expect it to behave like hemicellulose, also showing a strong decrease in $\mathrm{Tg}$ when wet. This has been added to the introduction. L7p5 Why is there any quote?

The sentence "lignin reaches an equilibrium ... free water." Is cited from Reference 26. This has been made clear in the text 
L33p4 "...can lead to debonding..." please add reference

References have been added

Material and Methods

L4p6 Flax preform and related composites are not described

The information on the flax material has been added, and the title of the section was changed to 2.1 Natural fibres and extraction.

L32p7 You assume that prior testing desorption is not significant. Have

you proof of that?

The sentence has been changed to make clear that we assume the 'moisture content' within the samples is considered unchanged (not the RH of the environment) prior to testing. Based on the weight measurement of the conditioning of the samples versus time it was shown that the moisture content changed less than $0.5 \%$ after 2 hours (for the sample conditioned at $\left.84 \circ \mathrm{RH}, 30{ }^{\circ} \mathrm{C}\right)$. Therefore, the change after 15 minutes is considered negligible, considering the logarithmic relationship between the moisture content and the $t^{\wedge}(1 / 2)$. This has been added to the text.

L38p7 Cycling is performed at $80^{\circ} \mathrm{C}$ and $80 \% \mathrm{RH}-1.2 \% \mathrm{RH}$ certainly to speed up stationary regime to be reached but it induce hygro-thermal coupling which need to be discussed. It is well known that applying various hygroscopic conditions at temperature close to $\mathrm{Tg}$ is more severe than far form Tg. For natural fibre Tg of pectins, hemicellulose will drastically decrease when moisturized...

Harsh conditions for the cycling of the bamboo fibre reinforced composites are chosen to 1) indeed speed up the stationary regime to be reached but 2) also to see to which extend damage can be created when cycling and what the effect of residual parenchyma is on that. The properties of the composites are tested in the dry state throughout the cycling experiment. This has been added to the materials and methods section.

L23p8 You calculate Young's modulus of composite. Are you sure that in the deformation range the relationship between stress and strain is linear? You should prefer Tensile modulus or apparent modulus. Please refer to recent articles of Shah et al, Berges et al or Boumaud et al ${ }^{*}$ M Berges, R Léger, V Placet, V Person, S Corn, X Gabrion, J Rousseau, E Ramasso, P Ienny, S Fontaine, Influence of moisture uptake on the static, cyclic and dynamic behaviour of unidirectional flax fibre-reinforced epoxy laminates, Compos A Appl Sci Manuf,, 2016, 88, 165-177

* Shah D, Damage in biocomposites: stiffness evolution of aligned plant fibre composites during monotonic and cyclic fatigue loading. Compos A Appl Sci Manuf, (2016) 83:160-168

*A Bourmaud, A Le Duigou, C Gourier, C Baley, Influence of processing temperature on mechanical performance of unidirectional polyamide 11-flax fibre composites, Industrial Crops and Products, Volume 84, 2016, 151-165 A stress strain curve figure has been added in section 3.2 and 3.4 , to show that the behaviour of the bamboo reinforced composites is linear. This behaviour is also found for technical bamboo fibres (though this is not part of this research work). The authors are well aware of the nonlinear behaviour of flax fibres, but for bamboo fibres this is not present. Therefore, the modulus is calculated according to the ASTM D3039 standard, in the 0.1-0.3\% strain range. A sentence clarifying this was added to the methods section.

Similarly, at fibre scale, it is well know that fibre exhibit a non linear behaviour which prevent a Young's modulus to be determined, please prefer tangeant modulus. In addition, it has been proved that the use of Rule of mixture for back calculation is questionable. 
* See Shah et al DU. Shah, RK. Nag, MJ. Clifford, Why do we observe significant differences between measured and 'back-calculated' properties of natural fibres? Cellulose, 2016, 23, 3, 1481-1490

The rule of mixture might indeed fail to predict the technical fibre properties accurately (as proven for flax fibres) though for bamboo fibres the measured technical fibre properties are in good agreement with the back calculated properties from the IFBT (this is part of another manuscript). Still the authors want to point out (regardless the (non) linear behaviour of the fibre) that the IFBT is a valid test, being a measure for the reinforcement the fibre brings to the composite. The difference with flax fibres, where two moduli can be determined has been added to the materials and methods section.

Results and Discussion

Mechanical properties are shown and discussed but tensile behaviour would have been very interesting to justify the term Young's modulus and elucidate the role of moisture on the non-linearity. A stress strain curve has been added in section 3.2 and 3.4 L50p10 "Reduction of stiffness is due to plasticization" but this mechanism is typically from reversible mechanism. Is there any proof of reversibility? (L18p13 for example)

In section 3.4 cyclic tests are performed which give insight in the reversibility of the effect of water. It was shown that the E-modulus for clean fibres (C3) in unchanged after 5 cycles, but if parenchyma is present and damage is induced a drop is seen. The text has been changed to avoid confusion regarding the reversibility. Instead of plasticization the focus is put on increased flexibility caused by the water.

L55-p10 You claim that in the literature, the increase of strength is not linked with better stress transfer. Please cite reference. The reference has been added

Then your explanation about increase of strength is confused. Please clarify.

The sentence has been rephrased in order to clarify

Relative Humidity is not inherent of material properties, for better

interpretation you should plot your graph of mechanical properties as a function of moisture content rather than RH. You should discuss the moisture content.

The graphs have been changed

There is no information about flax, it is missing to present a coherent article.

The main focus of this work is the behaviour of bamboo fibre reinforced composites, only for the DMA analysis flax is used as comparison, where the purpose was to investigate a fibre with different chemical

composition. This has been stated more clearly in the materials and method section 2.1

L12-p11 Comparison with literature is difficult when RH is used. Moisture content related to property variation is more relevant.

The graphs have been changed, though the references cited do not all

mention the EMC, where it was mentioned it is added to the text.

L33-p11 please add information in the table (Which fibre?)

This information has been added in all table captions

L46-p11 from 40 to $55 \mathrm{GPa}$

The 55 to $40 \mathrm{GPa}$ is in accordance with the change from 0 to $84 \% \mathrm{RH}$. The text has been changed to make this clear.

L58-p11 there is difference of moisture content between flax and bamboo composites, How to compare them? please comment

The comment refers to the DMA / Tg experiment. The bamboo composite has a higher moisture content than the flax composite, yet the flax composite 
shows a clear difference in Tg in the wet condition. This difference can only be expected to be more pronounced if the same water content as in the bamboo composite sample would be present. Therefore, this difference does not affect the conclusions made.

L13-p12 flax contains almost no lignin (OK) but what about its chemical composition? And the relationship with loss of properties. Please add references A reference has been added

L1p13 ...larger shift of Tg for flax composite than bamboo... The test has been carried out for UD, Assuming similar effect on the matrix, longitudinal properties of fibre must be altered. These properties are mainly due to cellulose content and MFA. So what is the role of lignin (for bamboo) and moisture sensitive polysaccharides (for flax) in the performance of fibres ?

A potential effect of fibre/matrix interface is not discussed as it may be different between flax and bamboo.

The previous two questions are related, and are therefore addressed together.

Bamboo consists out of a network of cellulose, hemicellulose with lignin, as a 3D polymer filling all the spaces in between. Flax consists out of cellulose and hemicellulose as well with mainly pectin bounding the elementary fibres together. Pectin and hemicelluloses are highly hydrophilic, and moisture will be absorbed mainly at these locations. This results in a homogeneous spread of water for the bamboo fibre, while in flax fibres there is also localised water absorption at the middle lamellae, reducing the interface stiffness and the global stiffness of the composite. This reflected in the decreased storage modulus of flax fibre reinforced composites. This has been added to the text.

The potential effect of the fibre/matrix Interface was not investigated, but the moisture uptake in the pectin layer in flax will affect the adhesion. Interface effects are therefore expected to be more pronounced in flax than in bamboo.

L13p13 "this is important finding..." Thus has already been shown by *Graupner et al N Graupner, H Fischer, G Ziegmann and J Mussig, Improvement and analysis of fibre/matrix adhesion of regenerated cellulose fibre reinforced PP-, MAPP- and PLA-composites by the use of Eucalyptus globulus lignin, Comp Part B, 66, 2014, 117-125 A sentence has been added to the text to point out that lignin can improve adhesion with thermoplastics, though the authors want to point out that the 'important finding' here is not the favourable effect of lignin on the van-der-Waals forces related to the fibre/matrix interaction. It is the unchanged Tg of lignin rich fibre composites at wet conditions, and due to the 3D-network-presence of the lignin, the mechanical properties remain high.

L33 p13 There are relevant references in the literature that have already shown effect of hygroscopic cycles on moisture content, moisture uptake kinetic and creation of porosity. Please, you need to highlight your originality

* Newman RH. Auto-accelerative water damage in an epoxy composite reinforced with plain-weave flax fabric. Compos Part A Appl Sci Manuf 2009;40:1615-20. doi:10.1016/j.compositesa.2009.07.010

*A Le Duigou and M Castro, Hygromorph Biocomposites : Effect of fibre content and interfacial strength on the actuation performances, Industrial Crops and Products, 99, 2017,142-149

*A Le Duigou, S Requile, J Beaugrand, F Scarpa and M Castro, Natural fibres actuators for smart bio-inspired hygromorph biocomposites, Smart Materials and Structures, 2017, 26, 12 
Hygroscopic cycles has been evidenced to have a slight effect on saturation but higher on sorption kinetic...due to porosity generation. A paragraph has been added to the text referring to this work L52p13 How the fibre content could be normalized to 40\%, please explain This has been implemented in the materials and methods section. L59 p13 "after a brief re-equilibrium to room temperature"... this is not clear

The sentence has been changed also in the materials and methods part L4 p14 Cleaning leads to debonding of fibres... please prove it This is the hypothesis the authors formulate, it has not been proven directly. Though the results (lower stiffness and higher strain to failure for the C3 fibres, are an indirect proof). The text has been altered

What is the influence of the cleanliness on the mechanical behavior? The text has been changed to make this more clear.

L44p14 You claim that porous parenchyma play a role in moisture absorption but in figure 7, C1, C2 and C3 do not exhibit statically different values.

L50-57p14 You hypothetize that parenchyma affect the sorption behavior and swell/shrink more than fibre. Can you prove it? There is no evidence in your manuscript

The previous two questions are related, and are therefore addressed together.

The parenchyma that is present on the fibres is too limited to increase the global EMC, even for the C3 type of fibres. However due to the location of the parenchyma (on the fibre surface) and the inherently low mechanical properties of the parenchyma, it will strongly affect the damage development leading to lower composite mechanical properties for less clean fibres when cycling is applied (swelling and shrinking of the fibre + parenchyma). The text has been changed.

L10p17 The evolution of porosity over cycles have not been performed on the same sample which bring difficulty for interpretation. You observed no evolution of porosity content over sorption/desorption cycles. That would have been interesting to compare with flax (the structure of the article is not consistent as flax is sometimes used as comparison). Again there are references that need to be discussed where porosity evolution is also investigated with flax/epoxy or flax/MAPP or jute/MAPP The references of flax and jute have been added, unfortunately evolution of porosity content over sorption/desorption were not a topic of this research. In the introduction it has also been highlighted better in which parts flax is used and why.

Reviewer \#2: This manuscript describes the mechanical and water absorption properties of bamboo fibre reinforced composites on both static and hygroscopic cyclic conditioning. Authors proposed an interesting point of view and establish indirectly relationship between mechanical property in wet or dry environmental condition and the amount of residual parenchyma according the 'grades of cleanliness'. This degree of cleanliness is achieved via a purely mechanical combed process. Independently of the effect of the process on the fiber content in the composite, the gradual removal of the parenchyma leads to maintain the mechanical properties after hygroscopic aging. These results confirm that the amount of residual parenchyma on the fibre has a significant effect on mechanical properties. This article report results derived from numerous analysis methods, like X-ray Computed Tomography used for a morphological analysis which is clearly detailed in the document. The formats of the paper is well conformed with the guidelines of submitting a manuscript to the journal. 
However, for purposes of different grade of cleanliness comparisons, the authors choose to standardise the reported results by normalizing the composites to a fibre volume fraction of $40 \%$. If it is possible to apply a mixture law for the Young's modulus, the operation remains uncertain for the strength and erratic for the deformations. At least for the deformations, the authors could free themselves from this standardization of the results or eliminate these results in deformations always questionable and which do not lead to any tangible conclusion. Look at Figure 3 and Figure 8 and the text referring to these figures.

I recommend this article to be published with some suggested corrections above and some other less critical ones below:

Line 40 page5: technical fibre change in technical fibre

This has been changed

Line 7 page 7 : indicate the pressure used

The text has been changed to make this clear

Line 42 page 10: what properties and how are the values of real fibre volume fraction corrected?

This has been added to the materials and methods sections

Line 5 page 12: "reinforced composites range between 19-27" change in "reinforced composites range between 25?-27".

This value has been corrected

Line 9 page 14: As discussed previously, this statement is incorrect "This would also lead to a higher strain to failure as was observed." A lower stress transfer, caused by possible debonding of the elementary fibres for the cleanest technical fibres C3; would cause a lower stiffness, but a clean fibre would have less stress concentrations and therefore fail later, leading to a higher strain to failure Line 37 page 14: As discussed previously, this sentence is not relevant in the context "The effect of cycling and the presence of parenchyma on the strain to failure is not so clear..."

The authors were not sure what exactly is meant here by the reviewer.

The following adjustments to the figures were implemented and are highlighted in the text.

Figure 4: specify in the legend that it is bamboo

Figure 5: specify in the legend that it is flax

Figure 9: specify the means of analysis in the legend (analysed by K-ray $\mathrm{CT}$ )

Figure 10: specify in the legend the type of cross sectional by referencing the images $[a), b), c), d)]$

Figure 8: the graph has been changed since there was an error in the strain of C1 5 cycles and C2 5 cycles, the results section has been changed accordingly 
Dear Editor,

We wish to submit our research paper entitled "Sorption behavior of bamboo fibre reinforced composites, why do they retain their properties?"

This manuscript has not been published elsewhere and is not under consideration by another journal. All authors have approved the manuscript and agree with its submission to Composites Part A.

In this paper the static and hygroscopic cyclic conditioning of bamboo fibre reinforced composites is investigated. Results show a smaller decrease in Young's modulus with moisture content as compared to flax fibre reinforced composites. The difference is explained by the chemical composition of the fibre, and demonstrated by dynamic mechanical analysis, where a clear difference is shown in the behaviour of wet and dry flax versus bamboo fibre reinforced composites. This research is novel, since it compares two types of natural fibres and looks for the underlying phenomena to explain the difference. Furthermore, the effect of the remaining parenchyma on the bamboo fibres when submitted to hygroscopic cycling is investigated and shows that clean fibres are beneficial for the long term properties. We believe this is an interesting topic for Composites Part A.

Kind regards, The authors 
Ms. Ref. No.: JCOMA-18-1563

Title: Sorption behaviour of bamboo fibre reinforced composites, why do they retain their properties?

Composites Part A

Dear Depuydt,

The referees have now completed reviewing your paper and their comments are given below. The paper is recommended to be accepted only after mandatory revisions. Before we can proceed, please let me have a point-by-point response to the issues raised in the reviews together with a revised version of the paper. A final decision will be made after receiving the revised version and your response.

Please clearly indicate where changes have been made, for example by using a different colour. If you are using MS Word, you can highlight changes using the "Track Changes" feature. In 'Tools', choose 'Track Changes', 'Highlight Changes' and tick 'Track changes while editing'.

Please note that, according to journal guidelines, revisions should be submitted within 30 days.

To submit a revision, please go to https://ees.elsevier.com/compositesa/ and login as an Author.

Your username is: delphine.depuydt@kuleuven.be

If you need to retrieve password details, please go to: http://ees.elsevier.com/compositesa/automail query.asp

On your Main Menu page is a folder entitled "Submissions Needing Revision". You will find your submission record there.

Composites Part A features the Interactive Plot Viewer, see: http://www.elsevier.com/interactiveplots. Interactive Plots provide easy access to the data behind plots. To include one with your article, please prepare a .csv file with your plot data and test it online at http://authortools.elsevier.com/interactiveplots/verification before submission as supplementary material.

With many thanks,

Kristiina Oksman, Ph.D.

Biocomposites editor

Composites Part A

Editor/referees' comments:

If the reviewer has uploaded his comments as an attachment you will need to login to your author main menu to download the attached file.

The authors would like to thank the editor and the reviewers for the time they've put in reviewing this manuscript. We believe the suggestions and comments helped to improve the text significantly.

Kind regards,

The authors 
Reviewer \#1: Manuscript $n^{\circ}$ JCOMA-18-1563 entitled "Sorption behaviour of bamboo fibre reinforced composites, why do they retain their properties?"

Although the topic is very interesting and deserves research to be focused on, the structure of the article is confusing and the quality of the results and interpretation are not sufficient to be published in Comp part A.

Introduction :

L5-p2 You mean that all natural fibres can compete with glass but it is not strictly right, bast fibres can but fruits fibres cannot.

This point has been added, it has been made clear that it mainly counts for bast and grass fibres.

L6-p2 Environmental benefit is cited for natural fibres and their composites, please cite original research articles

References have been added

L22p2 Moisture induced degradations are cited, please cite original research articles

References have been added

L52p2 "reduce" rather than "destroy"

This has been changed

L1p3 Please mention that table 1 is dedicated to natural fibre reinforced thermoset polymer

This has been added

L43p3 The review of the literature highlighting moisture induced degradation is interesting but is lacking from information dedicated to the relation between the biochemical composition of the fibre and the polysaccharide leashing. Two articles in the literature are available and have shown that leashing, depending on the fibre biochemistry is a drastic degradation scenario for natural fibres (This is exactly the topic of your article):

Please See :

*A le Duigou, A Bourmaud, and C Baley, In-situ evaluation of flax fibre degradation after water aging, Industrial Crops and Products, 2015, 70, 204-210

*A Le Duigou, S Requile, J Beaugrand, F Scarpa and M Castro, Natural fibres actuators for smart bioinspired hygromorph biocomposites, Smart Materials and Structures, 2017, 26, 12

The first paper referred to, studies the evolution of the mechanical properties of flax fibres (by nanoindentation) after the immersion of the composites. Nanoindentation was performed after drying of the samples, and a decrease in mechanical properties was found, which was linked to the leaching of polysaccharides, which lowered the load transfer between the microfibrils, resulting in lower properties. This research is very interesting, however, the proposed manuscript focuses on bamboo fibres, which differ in chemical composition from flax fibres, more specific, they contain almost no pectins. Chemical characterisation of bamboo in other (not yet published work) reveals a cellulose content of 55\%, hemicellulose $14 \%$ and lignin 31\% and $0.7 \mathrm{~g} / 100 \mathrm{~g}$ extractives (in neutral detergent solvent), this comprises soluble carbohydrates, lipids and proteins. For this reason leaching is far less important when it comes to bamboo fibres. Also, in this work the mechanical performance of bamboo and flax is compared in the moisture saturated phase in a humid environment, exposed to gaseous water, not liquid. No immersion is applied, and therefore leaching can only be minor, and cannot explain the difference in mechanical properties. For completeness of the manuscript the leaching phenomenon has been added to the text.

L1p5 You are talking about cellulose, hemicellulose and lignin... but what about pectins? Their presence has a great role especially for flax (in middle lamellae, primary and secondary cell wall) and they are very sensitive to moisture. Please add information

The information about the change in glass transition temperature referred to in this paper is based on the available measurements for wood, comprising the data on the main constituents of wood. Pectin is not one of them, and no information is available on that. Bamboo is very similar to wood, regarding its chemical composition, therefore this wood reference is very relevant. Information on 
the glass transition temperature of pectin in dry and wet condition is not available to the best of the authors' knowledge. Based on the structure of pectin, one might expect it to behave like hemicellulose, also showing a strong decrease in $\mathrm{Tg}$ when wet. This has been added to the introduction.

L7p5 Why is there any quote?

The sentence "lignin reaches an equilibrium ... free water." Is cited from Reference 26. This has been made clear in the text

L33p4 "...can lead to debonding..." please add reference

References have been added

\section{Material and Methods}

L4p6 Flax preform and related composites are not described

The information on the flax material has been added, and the title of the section was changed to 2.1 Natural fibres and extraction.

L32p7 You assume that prior testing desorption is not significant. Have you proof of that?

The sentence has been changed to make clear that we assume the 'moisture content' within the samples is considered unchanged (not the $\mathrm{RH}$ of the environment) prior to testing. Based on the weight measurement of the conditioning of the samples versus time it was shown that the moisture content changed less than $0.5 \%$ after 2 hours (for the sample conditioned at $84 \% \mathrm{RH}, 30{ }^{\circ} \mathrm{C}$ ). Therefore, the change after 15 minutes is considered negligible, considering the logarithmic relationship between the moisture content and the $t^{\wedge}(1 / 2)$. This has been added to the text.

L38p7 Cycling is performed at $80^{\circ} \mathrm{C}$ and $80 \% \mathrm{RH}-1.2 \% \mathrm{RH}$ certainly to speed up stationary regime to be reached but it induce hygro-thermal coupling which need to be discussed. It is well known that applying various hygroscopic conditions at temperature close to $\mathrm{Tg}$ is more severe than far form $\mathrm{Tg}$. For natural fibre Tg of pectins, hemicellulose will drastically decrease when moisturized...

Harsh conditions for the cycling of the bamboo fibre reinforced composites are chosen to 1 ) indeed speed up the stationary regime to be reached but 2) also to see to which extend damage can be created when cycling and what the effect of residual parenchyma is on that. The properties of the composites are tested in the dry state throughout the cycling experiment. This has been added to the materials and methods section.

L23p8 You calculate Young's modulus of composite. Are you sure that in the deformation range the relationship between stress and strain is linear? You should prefer Tensile modulus or apparent modulus. Please refer to recent articles of Shah et al, Berges et al or Boumaud et al

*M Berges, R Léger, V Placet, V Person, S Corn, X Gabrion, J Rousseau, E Ramasso, P lenny, S Fontaine, Influence of moisture uptake on the static, cyclic and dynamic behaviour of unidirectional flax fibre-reinforced epoxy laminates, Compos A Appl Sci Manuf,, 2016, 88, 165-177

*Shah D, Damage in biocomposites: stiffness evolution of aligned plant fibre composites during monotonic and cyclic fatigue loading. Compos A Appl Sci Manuf, (2016) 83:160-168

*A Bourmaud, A Le Duigou, C Gourier, C Baley, Influence of processing temperature on mechanical performance of unidirectional polyamide 11-flax fibre composites, Industrial Crops and Products, Volume 84, 2016, 151-165

A stress strain curve figure has been added in section 3.2 and 3.4, to show that the behaviour of the bamboo reinforced composites is linear. This behaviour is also found for technical bamboo fibres (though this is not part of this research work). The authors are well aware of the non-linear behaviour of flax fibres, but for bamboo fibres this is not present. Therefore, the modulus is calculated according to the ASTM D3039 standard, in the 0.1-0.3\% strain range. A sentence clarifying this was added to the methods section. 

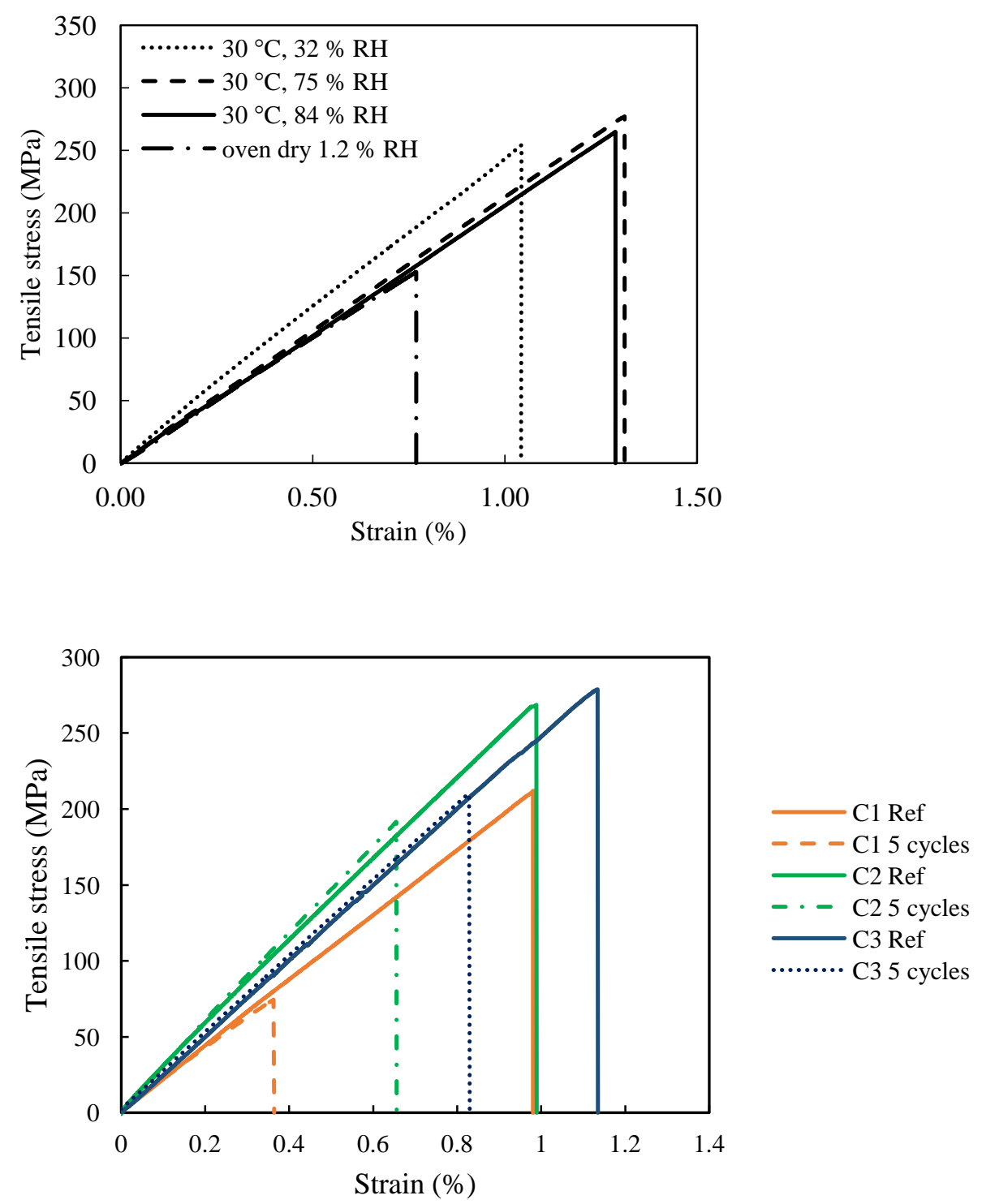

Similarly, at fibre scale, it is well know that fibre exhibit a non linear behaviour which prevent a Young's modulus to be determined, please prefer tangeant modulus. In addition, it has been proved that the use of Rule of mixture for back calculation is questionable.

*See Shah et al DU. Shah, RK. Nag, MJ. Clifford, Why do we observe significant differences between measured and 'back-calculated' properties of natural fibres? Cellulose, 2016, 23, 3, 1481-1490

The rule of mixture might indeed fail to predict the technical fibre properties accurately (as proven for flax fibres) though for bamboo fibres the measured technical fibre properties are in good agreement with the back calculated properties from the IFBT (this is part of another manuscript). Still the authors want to point out (regardless the (non)linear behaviour of the fibre) that the IFBT is a valid test, being a measure for the reinforcement the fibre brings to the composite. The difference with flax fibres, where two moduli can be determined has been added to the materials and methods section.

\section{Results and Discussion}

Mechanical properties are shown and discussed but tensile behaviour would have been very interesting to justify the term Young's modulus and elucidate the role of moisture on the nonlinearity. 
A stress strain curve has been added in section 3.2 and 3.4

L50p10 "Reduction of stiffness is due to plasticization" but this mechanism is typically from reversible mechanism. Is there any proof of reversibility? (L18p13 for example)

In section 3.4 cyclic tests are performed which give insight in the reversibility of the effect of water. It was shown that the E-modulus for clean fibres (C3) in unchanged after 5 cycles, but if parenchyma is present and damage is induced a drop is seen. The text has been changed to avoid confusion regarding the reversibility. Instead of plasticization the focus is put on increased flexibility caused by the water.

L55-p10 You claim that in the literature, the increase of strength is not linked with better stress transfer. Please cite reference. The reference has been added

Then your explanation about increase of strength is confused. Please clarify.

The sentence has been rephrased in order to clarify

Relative Humidity is not inherent of material properties, for better interpretation you should plot your graph of mechanical properties as a function of moisture content rather than $\mathrm{RH}$. You should discuss the moisture content.

The graphs have been changed

There is no information about flax, it is missing to present a coherent article.

The main focus of this work is the behaviour of bamboo fibre reinforced composites, only for the DMA analysis flax is used as comparison, where the purpose was to investigate a fibre with different chemical composition. This has been stated more clearly in the materials and method section 2.1

L12-p11 Comparison with literature is difficult when RH is used. Moisture content related to property variation is more relevant.

The graphs have been changed, though the references cited do not all mention the EMC, where it was mentioned it is added to the text.

L33-p11 please add information in the table (Which fibre?)

This information has been added in all table captions

L46-p11 from 40 to $55 \mathrm{GPa}$

The 55 to $40 \mathrm{GPa}$ is in accordance with the change from 0 to $84 \% \mathrm{RH}$. The text has been changed to make this clear.

L58-p11 there is difference of moisture content between flax and bamboo composites, How to compare them? please comment

The comment refers to the DMA / Tg experiment. The bamboo composite has a higher moisture content than the flax composite, yet the flax composite shows a clear difference in $\mathrm{Tg}$ in the wet condition. This difference can only be expected to be more pronounced if the same water content as in the bamboo composite sample would be present. Therefore, this difference does not affect the conclusions made.

L13-p12 flax contains almost no lignin (OK) but what about its chemical composition? And the relationship with loss of properties. Please add references $A$ reference has been added

L1p13 ...larger shift of Tg for flax composite than bamboo... The test has been carried out for UD, Assuming similar effect on the matrix, longitudinal properties of fibre must be altered. These properties are mainly due to cellulose content and MFA. So what is the role of lignin (for bamboo) and moisture sensitive polysaccharides (for flax) in the performance of fibres ?

A potential effect of fibre/matrix interface is not discussed as it may be different between flax and bamboo.

The previous two questions are related, and are therefore addressed together.

Bamboo consists out of a network of cellulose, hemicellulose with lignin, as a 3D polymer filling all the spaces in between. Flax consists out of cellulose and hemicellulose as well with mainly pectin bounding the elementary fibres together. Pectin and hemicelluloses are highly hydrophilic, and moisture will be absorbed mainly at these locations. This results in a homogeneous spread of water for the bamboo fibre, while in flax fibres there is also localised water absorption at the middle 
lamellae, reducing the interface stiffness and the global stiffness of the composite. This reflected in the decreased storage modulus of flax fibre reinforced composites. This has been added to the text. The potential effect of the fibre/matrix Interface was not investigated, but the moisture uptake in the pectin layer in flax will affect the adhesion. Interface effects are therefore expected to be more pronounced in flax than in bamboo.

L13p13 "this is important finding..." Thus has already been shown by

*Graupner et al N Graupner, H Fischer, G Ziegmann and J Mussig, Improvement and analysis of fibre/matrix adhesion of regenerated cellulose fibre reinforced PP-, MAPP- and PLA-composites by the use of Eucalyptus globulus lignin, Comp Part B, 66, 2014, 117-125

A sentence has been added to the text to point out that lignin can improve adhesion with thermoplastics, though the authors want to point out that the 'important finding' here is not the favourable effect of lignin on the van-der-Waals forces related to the fibre/matrix interaction. It is the unchanged $\mathrm{Tg}$ of lignin rich fibre composites at wet conditions, and due to the 3D-networkpresence of the lignin, the mechanical properties remain high.

L33 p13 There are relevant references in the literature that have already shown effect of hygroscopic cycles on moisture content, moisture uptake kinetic and creation of porosity. Please, you need to highlight your originality

* Newman RH. Auto-accelerative water damage in an epoxy composite reinforced with plain-weave flax fabric. Compos Part A Appl Sci Manuf 2009;40:1615-20. doi:10.1016/j.compositesa.2009.07.010

*A Le Duigou and M Castro, Hygromorph BioComposites : Effect of fibre content and interfacial strength on the actuation performances, Industrial Crops and Products, 99, 2017,142-149

*A Le Duigou, S Requile, J Beaugrand, F Scarpa and M Castro, Natural fibres actuators for smart bioinspired hygromorph biocomposites, Smart Materials and Structures, 2017, 26, 12

Hygroscopic cycles has been evidenced to have a slight effect on saturation but higher on sorption kinetic...due to porosity generation.

A paragraph has been added to the text referring to this work

L52p13 How the fibre content could be normalized to $40 \%$, please explain

This has been implemented in the materials and methods section.

L59 p13 "after a brief re-equilibrium to room temperature"... this is not clear

The sentence has been changed also in the materials and methods part

L4 p14 Cleaning leads to debonding of fibres... please prove it

This is the hypothesis the authors formulate, it has not been proven directly. Though the results (lower stiffness and higher strain to failure for the C3 fibres, are an indirect proof). The text has been altered

What is the influence of the cleanliness on the mechanical behavior?

The text has been changed to make this more clear.

L44p14 You claim that porous parenchyma play a role in moisture absorption but in figure 7, C1, C2 and $\mathrm{C} 3$ do not exhibit statically different values.

L50-57p14 You hypothetize that parenchyma affect the sorption behavior and swell/shrink more than fibre. Can you prove it? There is no evidence in your manuscript

The previous two questions are related, and are therefore addressed together.

The parenchyma that is present on the fibres is too limited to increase the global EMC, even for the C3 type of fibres. However due to the location of the parenchyma (on the fibre surface) and the inherently low mechanical properties of the parenchyma, it will strongly affect the damage development leading to lower composite mechanical properties for less clean fibres when cycling is applied (swelling and shrinking of the fibre + parenchyma). The text has been changed.

L10p17 The evolution of porosity over cycles have not been performed on the same sample which bring difficulty for interpretation. You observed no evolution of porosity content over sorption/desorption cycles. That would have been interesting to compare with flax (the structure of the article is not consistent as flax is sometimes used as comparison). Again there are references 
that need to be discussed where porosity evolution is also investigated with flax/epoxy or flax/MAPP or jute/MAPP

The references of flax and jute have been added, unfortunately evolution of porosity content over sorption/desorption were not a topic of this research. In the introduction it has also been highlighted better in which parts flax is used and why.

Reviewer \#2: This manuscript describes the mechanical and water absorption properties of bamboo fibre reinforced composites on both static and hygroscopic cyclic conditioning. Authors proposed an interesting point of view and establish indirectly relationship between mechanical property in wet or dry environmental condition and the amount of residual parenchyma according the 'grades of cleanliness'. This degree of cleanliness is achieved via a purely mechanical combed process. Independently of the effect of the process on the fiber content in the composite, the gradual removal of the parenchyma leads to maintain the mechanical properties after hygroscopic aging. These results confirm that the amount of residual parenchyma on the fibre has a significant effect on mechanical properties. This article report results derived from numerous analysis methods, like X-ray Computed Tomography used for a morphological analysis which is clearly detailed in the document.

The formats of the paper is well conformed with the guidelines of submitting a manuscript to the journal.

However, for purposes of different grade of cleanliness comparisons, the authors choose to standardise the reported results by normalizing the composites to a fibre volume fraction of $40 \%$. If it is possible to apply a mixture law for the Young's modulus, the operation remains uncertain for the strength and erratic for the deformations. At least for the deformations, the authors could free themselves from this standardization of the results or eliminate these results in deformations always questionable and which do not lead to any tangible conclusion. Look at Figure 3 and Figure 8 and the text referring to these figures.

I recommend this article to be published with some suggested corrections above and some other less critical ones below:

Line 40 page 5: technical fibre change in technical fibre

This has been changed

Line 7 page 7 : indicate the pressure used

The text has been changed to make this clear

Line 42 page 10: what properties and how are the values of real fibre volume fraction corrected?

This has been added to the materials and methods sections

Line 5 page 12: "reinforced composites range between 19-27" change in "reinforced composites range between 25 ? -27 ".

This value has been corrected

Line 9 page 14: As discussed previously, this statement is incorrect "This would also lead to a higher strain to failure as was observed."

A lower stress transfer, caused by possible debonding of the elementary fibres for the cleanest technical fibres C3; would cause a lower stiffness, but a clean fibre would have less stress concentrations and therefore fail later, leading to a higher strain to failure

Line 37 page 14: As discussed previously, this sentence is not relevant in the context "The effect of cycling and the presence of parenchyma on the strain to failure is not so clear..."

The authors were not sure what exactly is meant here by the reviewer.

The following adjustments to the figures were implemented and are highlighted in the text.

Figure 4: specify in the legend that it is bamboo

Figure 5: specify in the legend that it is flax 
Figure 9: specify the means of analysis in the legend (analysed by K-ray CT)

Figure 10: specify in the legend the type of cross sectional by referencing the images [a), b), c), d)]

Figure 8: the graph has been changed since there was an error in the strain of C1 5 cycles and C2 5 cycles, the results section has been changed accordingly 


\title{
Sorption behaviour of bamboo fibre reinforced composites, why do they retain their properties?
}

\author{
Delphine E.C. Depuydt ${ }^{\mathrm{a}}$, Jeroen Soete ${ }^{\mathrm{b}}$, Yalew D. Asfaw ${ }^{\mathrm{c}}$, Martine Wevers ${ }^{\mathrm{b}}$, Jan Ivens ${ }^{\mathrm{d}}$, Aart W. van Vuure ${ }^{\mathrm{a}}$ \\ ${ }^{a}$ KU Leuven, dept. Materials Engineering; Campus Groep T, Composite Materials Group, Andreas \\ Vesaliusstraat 13, 3000 Leuven, Belgium
}

\begin{abstract}
${ }^{\mathrm{b}}$ KU Leuven, dept. Materials Engineering; Structural Composites and Alloys, Integrity and Non-destructive Testing, Kasteelpark Arenberg 44, 3000 Leuven, Belgium

${ }^{c}$ Adama Science and Technology University, dept. Manufacturing Engineering, P.box 1888 Adama, Ethiopia

${ }^{\mathrm{d}}$ KU Leuven, dept. Materials Engineering; Technology Campus De Nayer, Composite Materials Group, Jan De Nayerlaan 5, 2860 Sint-Katelijne-Waver, Belgium
\end{abstract}

Keywords A. Biocomposite; B. Mechanical properties; C. Damage mechanics; D. Moisture

\begin{abstract}
The influence of moisture on the mechanical properties of bamboo fibre reinforced composites was assessed both for static and hygroscopic cyclic conditioning. Static conditioning revealed that bamboo fibre reinforced composites show a smaller decrease in Young's modulus with moisture content than other natural fibre reinforced composites such as for example flax based composites. The behaviour is explained by the chemical composition of the fibre and demonstrated by dynamic mechanical analysis that illustrates how composites made with fibres of high lignin content retain their glass transition temperature in moist conditions. The influence of hygroscopic cycling was also assessed, with emphasis on the influence of the remaining parenchyma on the fibre surface. Clean fibres, are beneficial for the long term behaviour, with less deterioration in properties. Porosity analysis was performed via X-ray computed tomography to provide insight into the material structure of the composite and the effects of hygroscopic cycling.
\end{abstract}

\section{Introduction}

The area of Natural Fibre Reinforced Composites (NFRC) is expanding, which is reflected in the increasing research and innovation activities worldwide [1-5]. This interest is nurtured by environmental and economic concerns, revealing the need for sustainable materials in order to keep up with the consumption of a growing world population [2]. The need for sustainable materials has been generally recognized, and governmental 
legislation pushes forward in a sustainable direction [3]. Natural fibres have inherent characteristics that make them a promising material for today's challenges. Due to their light weight and good specific mechanical properties (mainly for bast and grass fibres) they can compete with synthetic glass fibres [6]. The fact that these low-cost fibres originate from a sustainable source leads to environmental benefits [2, 7-9]. However, some challenges remain [3,5], amongst which moisture sensitivity is a very important one. When NFRC are brought into contact with water, it is mainly the hydrophilic natural fibre that absorbs the moisture, since the polymer matrix is usually relatively hydrophobic [10]. Moisture can be absorbed until the equilibrium moisture content is reached (EMC); a condition where the material is neither gaining nor losing moisture [11]. Moisture has a detrimental effect on the composite performance, since it can reduce fibre properties and cause fibre swelling and fibre matrix debonding, leading to increased porosities and micro crack contents, all resulting in a decrease of the composite properties [5, 12-15]. In recent years, engineers have been trying to understand, improve and predict the hygrothermal behaviour of natural fibre reinforced composites.

Natural fibres derived from plants consist of cellulose microfibrils embedded in a lignin and hemicellulose matrix [16]. Though cellulose, hemicellulose and lignin are generally the main constituents of the cell wall, depending on the type of fibre, other components like pectins, oils and waxes can be present as well. The cellulose microfibrils are organised in crystalline and amorphous regions and it has been shown that the amount of water absorbed is inversely related with the crystallinity, since the crystalline regions do not take up water $[17,18]$. The amorphous cellulose and the hemicellulose are hydrophilic whereas the lignin is more hydrophobic. Water can penetrate the composite either via diffusion inside the matrix, or by matrix imperfections (voids), or by capillarity along the fibre/matrix interface, via which it can reach the natural fibres [5]; in addition, water can easily penetrate the fibres when they are directly accessible at the composite surface. This will result in the breakage of hydrogen bonds between the molecules in the natural fibre, causing the hydroxyl groups or other polar groups to form new bonds with water [19]. In this way the water forces the cellulose microfibrils apart and reduces the rigidity of the cellulose structure and creates more free volume [20]. This 'plasticising of the fibre' is an important responsible factor for the observed changes in mechanical properties of NFRC when exposed to a moist environment. Another important problem is the occurrence of micro cracks at various locations due to the swelling and shrinking of the fibres with varying moisture content. 
Table 1 gives an overview of some references investigating the effect of moisture on the mechanical properties of unidirectional or woven natural fibre reinforced thermoset composites, when tested in moist or wet condition. The increase or decrease of the Young's modulus, strength and strain to failure is summarised. For some references, the absolute value was not given in the text but was derived from graphs; this is highlighted by an asterisk. Random architectures are not considered in this research, since the focus is to analyse the degradation of the fibre properties, which is more difficult to assess from random architectures. In longitudinal tensile loading of UD or woven architectures, the fibres are the main load bearing element, responsible for the measured properties. Any changes in their properties due to moisture, will immediately show in the measurements.

Apolinario et al. [21] showed the difference between flax and glass fibre reinforced polyester composites when immersed in water at $30{ }^{\circ} \mathrm{C}$. Both exhibited a Fickian absorption behaviour, but the saturated weight gain for the flax composites was around 6\%,15 times higher than for the glass fibre composites. The tensile modulus and strength of the glass fibre reinforced composite was only slightly affected whereas for the flax composite, the Young's modulus decreased $37 \%$ while the ultimate stress increased $34 \%$. The authors attributed the increase in strength to swelling of the fibres, but also plasticisation of the fibres will contribute. Scida et al. [22] studied the influence of moisture on the mechanical properties of unidirectional flax/epoxy composites. After saturation at $20{ }^{\circ} \mathrm{C}$ and $90 \%$ relative humidity (RH) for 38 days, the original stiffness of 26.6 GPa dropped back to only $12.0 \mathrm{GPa}$. For the tensile strength a decrease of $12 \%$ was found, while the strain to failure increased by $74 \%$. Conditioning at a higher temperature of $40{ }^{\circ} \mathrm{C}$ and $90 \% \mathrm{RH}$, resulted in a $2.8 \%$ higher EMC, which is in contrast with literature where it was shown that sorption isotherms decrease in absorbed water with increasing temperature [18, 23, 24]. Berges et al. [25] tested unidirectional flax epoxy composites, conditioned at $70{ }^{\circ} \mathrm{C}$ and $85 \% \mathrm{RH}$ and found a decrease of $36 \%$ for the Young's modulus, no difference for the strength and a $46 \%$ increase in strain to failure compared to the state at $21{ }^{\circ} \mathrm{C}$ and $50 \% \mathrm{RH}$. The decrease in stiffness is explained by the plasticising effect of water on the fibres and the matrix. Chilali et al. [26] studied the aging of a twill weave flax fibre reinforced epoxy and acrylic matrix. For both the thermoplastic and thermoset system similar results were found when immersing the samples in water till saturation at room temperature. The Young's modulus of the unaged samples, between 13-14 GPa, dropped to 
around $6 \mathrm{GPa}$. For the strength a decrease of $42 \%$ was measured, while the strain to failure increased up to $100 \%$. Tian et al. [10] investigated the behaviour of unidirectional ramie reinforced phenolic resin conditioned at $60^{\circ} \mathrm{C}$ and $85 \% \mathrm{RH}$ and found a rapid decrease of $60 \%$ in Young's modulus after 10 days of conditioning. Immersion experiments and experiments where the samples are conditioned at a certain temperature and $\mathrm{RH}$, might have a different leaching potential for water soluble components. As has been pointed out in the work of Le Duigou et al. [12], a decrease in mechanical properties after immersion of flax fibre reinforced composites was linked to the leaching of functional polysaccharides.

According to literature, the Young's modulus for NFRC brought into contact with moisture, typically decreases and the strain to failure increases. The change in strength will depend on the magnitude of these two effects. Though Symington et al. [27] and Placet et al. [28] saw an increase of the Young's modulus of elementary fibres up to a certain percentage of RH. This is explained by the rearrangement of the largely crystalline microfibrils enabled by the plasticising of the amorphous matrix. Plasticisation causes a reduction of the energy required to initiate chain mobility. For the strength both trends are found, each having different explanations. An increase in strength is explained by the swelling of the fibres, which fills the gap between fibre and matrix and improves the load transfer between fibre and matrix, thus leading to higher properties [21]. However, the authors want to point out that this explanation is not likely to explain the $34 \%$ increase in strength as in the work of Apolinario et al. [21]. Instead the authors believe that, if the modulus changes only moderately and the strain to failure increases substantially, the strength will increase. Whereas a decrease in strength is explained by the rupture of hydrogen bonds between the amorphous phase and crystalline fraction of the fibre, leading to a reduced strength [21]. All literature references revealed an increase in the strain to failure with increasing water content, where water acts as a plasticiser, softening the structure [29]. A critical remark must be made considering the literature, since the reference state of the composites is not always clearly defined. Sometimes comparison is made in relation to oven dry samples, in other cases to standard room conditions of $21^{\circ} \mathrm{C}$ and $50 \% \mathrm{RH}$.

In literature no results on unidirectional bamboo fibre reinforced composites can be found. First experiments conducted in our labs showed, however, that bamboo fibre reinforced composites have higher residual properties when subjected to a certain humidity $[30,31]$. In this research the relation between the change in 
mechanical properties due to moisture absorption and the composition of the fibre is investigated. It is known that the glass transition temperature of polymers, natural or synthetic, decreases when moisture is absorbed [32]. Studies on wood, containing natural polymers like cellulose, hemicellulose and lignin show that the glass transition temperature $\left(T_{g}\right)$ for the amorphous regions of dry cellulose ranges between $200-250{ }^{\circ} \mathrm{C}$ and for dry hemicellulose between $150-220{ }^{\circ} \mathrm{C}$ while it is $205^{\circ} \mathrm{C}$ for dry lignin [33]. These temperatures are quite similar, but this changes when the components are water-saturated: the $T_{g}$ of cellulose and hemicellulose decreases to subambient temperatures, whilst the $T_{g}$ of water-saturated lignin remains as high as $100{ }^{\circ} \mathrm{C}$. No information on the pectin $T_{g}$ was found in literature, though as it is akin to hemicellulose it can be assumed that the behaviour would be similar. The pronounced difference for lignin is explained by Back and Salmén [33] : "Lignin reaches an equilibrium state at a fairly low moisture content, after which the glass transition is not affected by a further increase. The additional water is not part of the homogeneous phase but is free water".

In order to further investigate the role of lignin in natural fibres, a fibre with a high lignin content, like bamboo is in this study compared with a fibre with a low lignin content, like flax. The $T_{g}$ of flax and bamboo fibre reinforced composites in dry and wet state is studied by dynamic mechanical analysis in order to reveal any possible differences. Since the $T_{g}$ is closely related with the evolution of the Young's modulus with temperature, it can be hypothesized that fibres with high lignin content will retain higher Young's modulus when brought into a moist climate.

The cyclic moisture uptake of bamboo fibre reinforced composites is also studied. With alternating periods of exposure to wet and dry conditions, the fibres will undergo swelling as well as shrinking. The difference in expansion between fibre and matrix can lead to debonding at the fibre/matrix interface $[14,34,35]$. In this research special attention is payed to the influence of remaining parenchyma tissue on the mechanical properties of the bamboo fibre reinforced composites. In this research the terminology of elementary fibre, referring to a single plant cell, and technical fibre, being a bundle of elementary fibres, is used.

The technical fibres are extracted from a culm by a mechanical process separating them from the surrounding parenchyma tissue. Parenchyma tissue differs from fibre tissue as the cells have a larger diameter and much larger cell lumen and typically thinner cell walls. It can be considered as a more open, less dense structure 
[36], almost foam-like. In literature research has been conducted on the microfibril orientation of bamboo

fibres and parenchyma and the respective angles found are around $10^{\circ}$ for the fibres and $45^{\circ}$ for the parenchyma [37, 38]. The microfibril angle of the cellulose fibrils within the parenchyma cells is much higher, further explaining the lower properties of the tissue. The parenchyma tissue is also expected to be less crystalline, which potentially leads to more water absorption, as shown in [39].

\section{Materials and Methods}

\subsection{Natural fibres and extraction}

Bamboo culms were harvested from a typical bamboo plantation in Colombia, in the Coffee Region at 1300 meters above sea level with an annual average temperature of $23{ }^{\circ} \mathrm{C}$ and annual average precipitation of 2200 $\mathrm{mm}$ and relative humidity of $80 \%$ [40]. Fibres were extracted from the Guadua angustifolia Kunth (GAK), via a purely mechanical process developed at KU Leuven [41].

After extraction, some parenchyma is still present on the fibre surface. In this research the influence of the presence of parenchyma is investigated during hygroscopic cycling of the samples. Three different 'grades of cleanliness' are used, referred to as $\mathrm{C} 1, \mathrm{C} 2$ and $\mathrm{C} 3$. For $\mathrm{C} 1$, the fibres were combed with a very rough comb to disentangle and align them. By applying this procedure only a very small amount of parenchyma, that was already loose, is removed from between the fibres. For the $\mathrm{C} 2$ and $\mathrm{C} 3$ cleanliness level, the fibres are brushed manually in order to remove the parenchyma $[40,41]$. C2 represents the standard procedure, and for $\mathrm{C} 3$ extra care is taken to remove all of the parenchyma.

This work focusses on bamboo fibre reinforced composites, but in order to investigate the influence of the chemical composition on the glass transition temperature, flax composites (consisting of fibres with a low lignin content) were also studied and compared in the dynamic mechanical analysis (DMA). Unidirectional flaxtape, supplied by Lineo NV (Belgium) was used for the production of the flax fibre reinforced composites.

\subsection{Diameter determination of extracted fibres}

The diameter of the extracted fibres was determined in order to quantify their grades of cleanliness. The algorithm used for the diameter determination is described by Hendrickx et al. [42] and starts from a flatbed 
scanned image at 1200 dpi. After thresholding, to separate the fibres from the background, and morphological operations to clean the image, the fibre diameter was determined. First, the middle of the fibre was determined by searching local maxima and then the Euclidean distance was calculated, which equals $1 / 2$ diameter. This procedure is applied for every pixel along the fibre length. Around 30 technical fibres were measured for each species with a length of around $15 \mathrm{~cm}$, leading to more than 200.000 diameter measured points.

\subsection{Preparation of the impregnated fibre bundles}

Impregnated Fibre Bundle Tests (IFBT) were prepared as described in Bensadoun et al. [43]. Unidirectional composites were made in order to study the mechanical properties of the composites. The bamboo fibres were dried for at least 4 days at $60{ }^{\circ} \mathrm{C}$ prior to production and weighing. Composites of $250 \times 10 \times 2 \mathrm{~mm}$ were made with a target volume fraction of $40 \%$ fibres. The volume fraction is calculated from the weight of the fibres, assuming a bamboo fibre density of $1.4 \mathrm{~g} / \mathrm{cm}^{3}$. Epikote 828 LVEL epoxy with a 1,2diaminocyclohexane (Dytek DCH-99) hardener from Hexion was used as matrix. For the production of IFBT, the impregnated fibres were compacted in the mold to tensile bars (no vacuum), with a thickness controlled by spacers. The compaction pressure was not controlled. The samples were cured at $75{ }^{\circ} \mathrm{C}$ and post-curing was done at $150{ }^{\circ} \mathrm{C}$ for 1 hour.

\subsection{Hygroscopic equilibrium conditioning}

Composite samples were prepared with bamboo fibres of the $\mathrm{C} 2$ cleanliness level and conditioned at 3 different relative humidities $(\mathrm{RH})$ at a fixed temperature of $30{ }^{\circ} \mathrm{C}$. The different relative humidities were obtained with salt baths. Saturated solutions of $\mathrm{KCl}, \mathrm{NaCl}$, and $\mathrm{MgCl}_{2}$, were used to reach a relative humidity of $32 \%, 75 \%$ and $84 \%$ respectively at $30{ }^{\circ} \mathrm{C}$ [44]. The conditions in the salt bath were verified with a relative humidity data logger Testo $174 \mathrm{H}$ (Testo, Belgium) and no more than $1 \%$ deviation was found for the high relative humidities and up to $2 \%$ difference for the RH of $32 \%$. The oven dry sample state was obtained by drying in an oven at $80{ }^{\circ} \mathrm{C}(\mathrm{RH} 1.2 \%)$. Samples were judged to be in equilibrium when a weight change of less than $0.1 \%$ was found between two consecutive measurements, which was reached after 6 weeks. Samples were no longer than 15 minutes out of their respective salt bath before testing, therefore the moisture content within the sample is assumed to be nearly unchanged, though the temperature of testing is room temperature. 


\subsection{Hygroscopic cycling}

Samples were prepared with the three different grades of cleanliness. Hygroscopic cycling of the specimens was done by alternating between a wet and a dry environment. Saturation in the wet condition at $80{ }^{\circ} \mathrm{C}$ and 80 $\% \mathrm{RH}$ was reached within one week and it required the same amount of time to reach equilibrium with the dry condition in the oven $(1.2 \% \mathrm{RH})$ at $80{ }^{\circ} \mathrm{C}$. Saturation was verified with the same criteria as for conditioning of the samples. In this hygroscopic cycling research the wet condition was established by means of a Weiss Technik WKL 64/40 climate chamber (Weiss Technik, Belgium). After the cycling, the composites were conditioned to the oven dry state and the residual mechanical properties were tested. These rather harsh conditions of cycling were chosen to 1) speed up the stationary regime to be reached and 2) to see to which extend damage can be created when cycling and what the effect of residual parenchyma is on that. Reference samples were tested as well, which were kept in the oven at $80{ }^{\circ} \mathrm{C}$ after post curing. All the tests were performed on samples conditioned to the oven dry state, and were never longer than 15 minutes out of the oven prior to testing, however, tests were performed at room temperature. Weight analysis showed that the change in the sample's moisture content is negligible over this time period. The equilibrium moisture content (EMC) was calculated after every cycle, according to Eq. 1 . Where $\mathrm{m}_{\mathrm{eq}}$ is the mass of the sample at equilibrium and $m_{d}$ the initial mass of the dry sample before cycling.

Water content $=\frac{m_{e q}-m_{d}}{m_{d}}$

\subsection{Tensile test}

Tensile tests were performed according to the ASTM D3039 standard on an Instron 4467 tensile testing machine with a $5 \mathrm{kN}$ load cell and a crosshead displacement of $2 \mathrm{~mm} / \mathrm{min}$. The statically conditioned samples were tested at their relative humidities and the hygroscopic cycling samples in oven dry state. The specimens were gripped with pneumatic grips at 6 bars. The specimen gauge length was $15 \mathrm{~cm}$ and an extensometer of $2.5 \mathrm{~cm}$ was used to measure the strain of the specimens. 5 to 6 samples were tested per species. The Young's modulus was calculated as the slope of the stress-strain curve in the $0.1-0.3 \%$ strain interval. Bensadoun et al. [43] proposed to calculate two moduli for flax fibre reinforced composites, due to the non-linear behaviour. The bamboo fibres yield linear behaviour, therefore only one moduli was calculated. To detect significant 
differences between two group means, a two-sided t-test was performed with a significance level $\alpha$ of 0.05 . To compare multiple group means a two sided Analysis of Variance (ANOVA) is performed $(\alpha=0.05)$ with a Tukey HSD test to reveal which groups are significantly different from each other. Back calculated fibre Young's modulus and strength are obtained via the rule of mixture according to Eq.2 and Eq. 3. With $E_{f}$ and $E_{m}$ the fibre and matrix modulus, $\sigma_{f}$ and $\sigma_{m}^{\prime}$ the fibre and matrix tensile stress (at the fibre failure strain) and $V_{f}$ and $V_{m}$ the fibre and matrix volume fraction. IFBT gives a direct measurement of the achievable fibre reinforcement within the composite.

$E_{c}=V_{f} E_{f}+V_{m} E_{m}$

$\sigma_{c}=V_{f} \sigma_{f}+V_{m} \sigma_{m}^{\prime}$

\subsection{Determination of the glass transition temperature $\left(T_{g}\right)$}

To study the effect of moisture on the glass transition temperature of bamboo and flax fibre reinforced composites, samples were prepared in a similar way as for the IFBT. Specimens were cut to $60 \times 10 \times 2 \mathrm{~mm}$. Conditioning was performed in the climate chamber at $80{ }^{\circ} \mathrm{C}$ and $80 \% \mathrm{RH}$ for the wet samples, and in the oven $\left(80{ }^{\circ} \mathrm{C}\right.$ and $\left.1.2 \% \mathrm{RH}\right)$ for the dry samples, for at least one week. Dynamic mechanical analysis (DMA) was performed using a DMA Q800 V7.5 according to the ASTM E1640 -13 standard. The 3 point bending mode was used and wet samples were scanned over a temperature range of 0 to $210{ }^{\circ} \mathrm{C}$ and dry samples from room temperature to $210^{\circ} \mathrm{C}$ with a heating rate of $1^{\circ} \mathrm{C} / \mathrm{min}$. There was no humidity control inside the DMA, but the exposure times were deemed low enough to initially maintain the conditioned states. Three samples of each material and condition were tested. The frequency of the oscillations was fixed at $1 \mathrm{~Hz}$ and a strain amplitude of $0.05 \%$ with a preload of $0.01 \mathrm{~N}$ was applied. The storage modulus (E'), loss modulus (E”) and material loss factor $(\tan \delta)$ were collected during the test. The glass transition temperature is determined from the material loss factor versus temperature curve. To detect significant differences between two group means, a two-sided t-test was performed with a significance level $\alpha$ of 0.05 .

\subsection{Analysis of the porosities}

$\mathrm{X}$-ray Computed Tomography (XCT) provides the means to acquire 3D images of samples in a nondestructive way, visualizing both the material composition and its internal architecture at the microscopic 
level by using X-rays [45-47]. X-ray CT scans of specimens of roughly 7 × 3 x $2 \mathrm{~mm}$, cut from the tensile bars of the hygroscopic cycling specimens, were taken. For each level of cleanliness, one specimen cut from a reference tensile test sample and one from a sample after 5 hygroscopic cycles was analysed. Scans were performed on a Phoenix Nanotom S $180 \mathrm{kV} \mu \mathrm{CT}$ system from General Electric to determine the sample porosity. Scans were performed with a Molybdenum target installed, in nanofocus mode 1, and no additional filter materials were used. The voltage for all scans was set to $66 \mathrm{kV}$ and the current to $227 \mu \mathrm{A}$. A scan time of 20 minutes was achieved in the fast scan mode, in which frame averaging and image skip are disabled. During one scan, 2400 radiographic projections are taken over a $360^{\circ}$ rotation. The exposure time was set to $500 \mathrm{~ms}$, and an isotropic voxel size of $2 \mu \mathrm{m}$ was achieved during scanning. The data was further processed using the 2D/3D image analysis software Avizo Fire (v7) and Dataviewer (1.5.2.4).

In a first step the 'total porosities' were separated from fibres and matrix. For this step a double threshold hysteresis function [48] was used, which returns a binary version of the original gray-scale image, based on two predefined thresholds (a weak one, $\mathrm{T}_{\mathrm{w}}$ and a strong one, $\mathrm{T}_{\mathrm{s}}$ ). Gray values in the histogram below $\mathrm{T}_{\mathrm{w}}$ are labeled porosity in the segmented image, while those above $T_{s}$ are labeled as material. Subsequently, gray levels that fall in between $T_{w}$ and $T_{s}$ are labeled as porosity or material, depending on their 4-way connectivity to labeled areas in the segmented image.

By means of the 2D/3D image analysis software the histogram of the images containing only the pores was further divided. First the 'matrix porosities' were filtered out based on their density, higher sphericity and lower surface to volume ratio, leaving only the 'parenchyma and fibre porosities'. From that the 'fibre porosities' were selected by applying a geometrical boundary, limiting the fibre porosities (lumen) to a diameter of $25 \mu \mathrm{m}$. Typical lumen sizes in literature range between $2-20 \mu \mathrm{m}$ [36, 49]. After this thresholding the 3D porosity of the specimens was calculated based on the marching cubes volume model [50], and was calculated for $2 \mathrm{~mm}$ of specimen length for 1 sample per material.

Further visualisation was obtained with the DataViewer software, showing the cross sectional views of the different specimens. These sections were also visually investigated to see if typical damage was initiated by the hygroscopic cycling. 3D volume renderings of the porosity, colour coded for the type of porosities, were generated in Avizo. 


\section{Results and Discussion}

\subsection{Diameter characterisation of the fibres depending on the cleanliness}

Sections from the flatbed scans of the fibres with different degrees of cleanliness are shown in Figure 1. From the pictures it can be seen that the diameter of each fibre becomes smaller and more constant, when moving from $\mathrm{C} 1$ to $\mathrm{C} 3$, due to the removal of parenchyma. This is also visible in the diameter distribution of each scanned image, as shown in Figure 2. The distribution curve narrows moving from $\mathrm{C} 1$ to $\mathrm{C} 3$. The diameter distribution of $\mathrm{C} 1$ is the broadest, with the largest measured diameter of $1778 \mu \mathrm{m}$. The average diameter value of the different distributions is $393 \mu \mathrm{m}$ for $\mathrm{C} 1,247 \mu \mathrm{m}$ for $\mathrm{C} 2$ and $239 \mu \mathrm{m}$ for $\mathrm{C} 3$. All the distributions are bimodal, with the first mode corresponding to the small fibres present at the edges of the technical fibres.

\subsection{Properties in moist condition}

Bamboo fibre reinforced composited (fibres of $\mathrm{C} 2$ cleanliness) were conditioned at different relative humidities. Figure 3 shows the mechanical properties in function of the equilibrium moisture content (EMC) of the composites. The oven dry samples had an average volume fraction of $33 \pm 1 \%$, while the samples conditioned in the salt baths had an overall volume fraction of $44 \pm 4 \%$, for Figure 3 the composite's Young's modulus and strength were normalised to a fibre volume fraction of $40 \%$. The decrease in Young's modulus and increase in strain to failure is in agreement with literature on other natural fibres (Table 1) and can be explained by the flexibilizing effect of water on the bamboo fibres. In this experiment an increase in the strength of the composite is found, which is not believed to be caused by an improved stress transfer caused by swelling of the fibres as stated by Apolinario et al. [21], but rather by the minor decrease in stiffness, causing the increase in strain to dominate, which in turn results in an improved ultimate tensile strength. In Figure 4 a typical stress-strain curve of the composites conditioned at different relative humidities is given and a linear behaviour can be detected. This is in contrast with the non-linear behaviour noted for flax fibres composites $[25,51]$.

In literature [6], where bamboo composites were conditioned at $20^{\circ} \mathrm{C}$ and $50 \% \mathrm{RH}$, a Young's modulus of 18 $\pm 1 \mathrm{GPa}$ and a strength of $222 \pm 13 \mathrm{MPa}$ was found. In this research a slightly higher temperature is used (30 ${ }^{\circ} \mathrm{C}$ ), which is expected to lead to a lower EMC at $50 \% \mathrm{RH}$, and therefore a somewhat higher Young's 
modulus. Considering that the temperature difference is small, this effect is expected to be minor, and comparing the data it is seen that the results are in agreement.

In the work of Scida et al. [22] similar experiments were performed and at $20{ }^{\circ} \mathrm{C}$ and $90 \% \mathrm{RH}(\mathrm{EMC} 4.1 \%$ ), the Young's modulus of the flax fibre reinforced composites dropped $55 \%$ whereas in this work for bamboo fibre reinforced composites at $84 \% \mathrm{RH}(\mathrm{EMC} 6.8 \%)$, a drop of only $25 \%$ is found. A similar decrease in the properties of flax fibre reinforced epoxy was found in the work of Perremans et al. [52] where a $60 \%$ decrease in Young's modulus for samples conditioned at room temperature and $90 \% \mathrm{RH}$ was found compared to room temperature and $50 \% \mathrm{RH}$. Therefore it is concluded that the decrease in Young's modulus of the bamboo fibre reinforced composites is less than half that of a flax fibre reinforced composite when exposed to high $\mathrm{RH}$. The difference in behaviour will be further investigated in the next section, where the thermomechanical behaviour of wet and dry flax and bamboo fibre reinforced composites is studied.

Table 2 shows the back calculated fibre Young's modulus and strength of the considered bamboo composites. Perrier et al. [53] studied the damage development of hemp/epoxy composites by X-ray CT after water ageing. The latter authors did not observe any damage in the scan of a wet sample, but after removal from the water, desorption took place and cracks started to appear. Based on these findings, it is assumed that in one swelling step the fibre-matrix interface does not yet get damaged, and the back calculated properties represent the fibre properties at increased relative humidity. An increase in EMC from $0 \%$ to $6.8 \%$ results in a decrease of the Young's modulus from 55 to $40 \mathrm{GPa}$ and an increase in strength from 516 to $559 \mathrm{MPa}$.

\subsection{Influence of moisture on the glass transition temperature $\left(T_{g}\right)$ of bamboo and flax composites} Dynamic mechanical analysis was performed to reveal any existing difference between flax fibre and bamboo fibre reinforced composites in the dry $\left(80{ }^{\circ} \mathrm{C} \mid 1.2 \% \mathrm{RH}\right)$ and wet state $\left(80^{\circ} \mathrm{C} \mid 80 \% \mathrm{RH}\right)$. Both fibres were embedded in an epoxy matrix and conditioned prior to the DMA measurements. At these conditions wet bamboo and flax fibre reinforced composites contain respectively 5 - $6 \%$ and $3.5-4.5 \%$ moisture. Figure 4 and Figure 5 show the storage modulus and loss modulus in function of temperature, for a bamboo and flax fibre reinforced composite respectively. In each figure an example of a dry and wet conditioned sample is given. The measured storage moduli at $30{ }^{\circ} \mathrm{C}$ for the bamboo fibre reinforced composites range between 26 - 
$27 \mathrm{GPa}$ and for the flax fibre reinforced composites between 21 - $26 \mathrm{GPa}$ including wet and dry specimens. Since the storage modulus represents the elastic behaviour of the material, it can be compared with the stiffness of the composites in a tensile test. Comparing to literature and Figure 3, these values are in agreement.

The glass transition temperature can be defined in different ways, either as the sudden drop in the storage modulus (E'), or as the peak in the loss modulus (E") or loss factor (tan $\delta)$. In Figure 5, for the bamboo fibre reinforced sample, no real glass transition is observed below $200{ }^{\circ} \mathrm{C}$, only a secondary transition. There is no real drop in the E' and there is a small peak in E" between 140 and $150{ }^{\circ} \mathrm{C}$. For this secondary transition, no clear difference can be found comparing the transition temperature for the dry and wet conditioned sample. In Figure 6 the storage modulus and loss modulus for the flax fibre reinforced sample are given, where a clear shift in $T_{g}$ is seen both for the storage modulus and loss modulus. For the flax reinforced wet conditioned samples the $T_{g}$ shifts to lower temperatures. For further analysis the $T_{g}$ is determined as the peak of the loss factor to temperature curve.

The overview of the loss factor curves in function of the temperature for all the measured specimens is shown in Figure 7, and Table 2 lists the (glass) transition temperatures defined as the temperature at the peak value of the loss factor. For the flax composites two groups are seen, one with high $T_{g}$ for the dry composite, and one with low $T_{g}$ for the wet composite. This indicates a difference in behaviour between wet bamboo fibre and flax fibre reinforced composite. The average $T_{g}$ for flax fibre reinforced composites in the dry and wet state is respectively $166{ }^{\circ} \mathrm{C}$ and $149{ }^{\circ} \mathrm{C}$, while for bamboo fibre reinforced composites there is only a secondary transition at $143{ }^{\circ} \mathrm{C}$ and $145{ }^{\circ} \mathrm{C}$. A t-test reveals that the difference in population means for the bamboo fibre reinforced composite is non-significant $(\alpha=0,05)$, while for the flax based composite it is significant with an average $T_{g}$ drop of $17{ }^{\circ} \mathrm{C}$. From Figure 5 it is also seen that the storage modulus (E') of the bamboo fibre reinforced composites retains high values, even above the secondary transition temperature, whereas for flax a sharp drop can be observed.

These results indicate a larger shift in temperature transition for the flax fibre reinforced composites than for the bamboo fibre reinforced composites. If a $T_{g}$ for the bamboo fibre composites is present, it will take place above $200{ }^{\circ} \mathrm{C}$, which is generally seen as a temperature above which thermal degradation of natural fibres 
occurs. The explanation for the difference in thermal behaviour is sought in the amount of lignin present in the fibre. Literature has shown that lignin, being a 3D polymer, retains a higher $T_{g}$ value in moist conditions [33]. Flax, a fibre with almost no lignin [2], therefore is more sensitive to moisture with regard to loss of mechanical properties. Especially because the absorbed water will mainly be localised in the vicinity of the hemicellulose in the cell wall and the pectin rich middle lamellae. By the softening of the middle lamellae, the integrity of the fibre is decreased, which results in a drop in storage modulus. Bamboo fibres only possess very small amounts of pectin [2], and the water absorbed by the hemicellulose, will be more homogeneously distributed. Additionally, the 3D network of lignin in bamboo composites, of which the $T_{g}$ is less affected by moisture, will provide higher structural integrity in moist environments. This is an important finding that can help in how to modify natural fibres for moisture sensitive applications. Lignin also has a positive influence on the fibre-matrix adhesion, as shown by Graupner et al. [54], by lignin-treating lyocell fibres an improved adhesion was found between the fibres and the thermoplastic matrix used.

It can also be seen that both storage and loss modulus of bamboo fibre composite stay largely the same between dry and wet conditions, with a limited value of $\tan \delta$ at the secondary transition. For a flax fibre composite, the storage modulus is clearly lower in the wet condition over the entire temperature range and the loss factor is more than 3 times higher at the $T_{g}$ than for a bamboo fibre composite at the secondary transition. This demonstrates once more the stronger flexibilisation of the flax fibre in wet conditions, while basically having no effect on the bamboo fibre composite properties.

\subsection{Influence of hygroscopic cycling and parenchyma amount on the mechanical properties}

Besides the static moisture behaviour, the cyclic moisture behaviour of bamboo fibre reinforced composites was assessed. The average volume fraction of all the produced samples was $37 \pm 4 \%, 41 \pm 5 \%$ and $49 \pm 4 \%$ for the $\mathrm{C} 1, \mathrm{C} 2$ and $\mathrm{C} 3$ composites, respectively. Figure 8 shows the equilibrium moisture content determined in each cycle via Eq. 1. For all samples the average EMC varies between $5-6 \%$. A different evolution over time is seen for samples with a different cleanliness. It could be expected to see an increase in EMC over time, as the sample possibly accumulates damage during hygroscopic cycling, however there is no clear indication of this. Research of Newman et al. [13] on the hygroscopic cycling of flax/epoxy composites, did show an increase in water uptake and pore volume with an increasing number of cycles. However, an even more 
pronounced effect on the diffusion kinetics was seen with more cycles. Increased porosity and diffusion kinetics were also reported by Le Duigou et al. $[55,56]$ in their work on hygromorph biocomposites studying flax/MAPP and jute/MAPP. The effect of cycling on the diffusion kinetics of bamboo fibre reinforced composites has to be further quantified/demonstrated in future research.

Figure 9 and Table 4 give an overview of the results of the mechanical tests, with the Young's modulus and tensile strength normalised to a volume fraction of $40 \%$ fibres. In Figure 9 the white bars represent the composite properties of the reference samples, tested before hygroscopic cycling, and in orange the results after 5 cycles are shown. All the tests were performed on samples conditioned to the oven dry state, though testing was performed at room temperature, but the effect on the EMC and $\mathrm{RH}$ by this brief change in conditions is considered negligible.

A typical stress-strain curve of each combination (cleanliness and before or after cycling) is given as well in Figure 9 and again linear behaviour is noted before but also after cycling. An ANOVA test $(\alpha=0.05)$ was performed to compare the different means obtained from the IFBT. For the Young's modulus the composite made with the cleanest fibres (C3) shows the lowest modulus, significantly different from C2. The high level of cleaning is assumed to lead to some debonding between elementary fibres, lowering the stress transfer and enhancing the sliding within the technical fibres. This would also lead to a higher strain to failure, as was observed. In agreement with the Young's modulus, the tensile strength seems to be the highest for $\mathrm{C} 2$, and lower again for $\mathrm{C} 3$ cleanliness, yet the differences between the three grades are not significant. The samples with C3 fibres showed as mentioned a significantly higher strain to failure. Compared to literature [6], the mechanical properties of the bamboo composites are in agreement or even better. Based on these results, the amount of residual parenchyma on the fibre surface has an insignificant effect on the longitudinal mechanical properties; it is, however, likely that the cleanliness plays an important role on the transverse properties. When hygroscopic cycling is applied to the composite, the effect of parenchyma can become more important. Fibre swelling and shrinking will occur, and since the parenchyma is located at the fibre/matrix interface and has inherent lower mechanical properties and possible higher moisture sorption, this is expected to affect the damage development. 
No matter the cleanliness level of the fibres within the composites, no Young's modulus change was found between the reference sample and after hygroscopic cycling. The strength for all composites decreased after cycling, where the cleanest fibres had a $22 \%$ drop and the fibres with the most parenchyma present showed a $61 \%$ drop in strength. The composite strain to failure after cycling is related to the parenchyma content present on the fibre surface, for the cleanest fibres the smallest decrease is seen, $26 \%$, while for the fibres with the highest amount of parenchyma a large decrease of the strain to failure of $62 \%$ is found.

The reduced mechanical properties found after hygroscopic cycling for composites with higher parenchyma content can be explained by the location of the parenchyma and the fact that the material has low mechanical properties and is more prone to water sorption. The parenchyma of a bamboo plant, is located at the surface of the fibre, separating the fibre from the matrix. Hygroscopic cycling, leads to fibre swelling and shrinking. This deformation will likely damage the interface between the fibre and matrix, and lead to less optimal stress transfer from one fibre to another. The sorption properties of parenchyma have to be investigated in more detail, in order to make a statement on the difference in swelling of the parenchyma versus the fibre. The current study clearly demonstrates that the presence of parenchyma clearly influences the durability of the bamboo fibre reinforced composite.

No back calculated fibre properties are given, because some of the degradation effects are most likely interface-related.

\subsection{Characterisation of the porosities of the composites}

Figure 10 shows the $\mathrm{XY}$ cross sectional views of the specimens analysed via X-ray CT, cut from a tensile bar sample. It needs to be pointed out that the specimens analysed after hygroscopic cycling originate from different tensile bar samples than reference specimens. From the images it can be seen that the $\mathrm{C} 1$ specimens contained much higher porosities (dark grey) than the $\mathrm{C} 3$ specimens. The present porosities can be divided in three groups: matrix porosities, parenchyma porosities and fibre porosities. Matrix porosities can be considered as a defect that originated during the production of the composite, whereas parenchyma and fibre porosities are inherent to the structure of the cell, which contains a lumen in the middle of the cell. For means 
of clarification an example of each of the porosity groups is highlighted in colour in Figure 10 on the $\mathrm{C} 1$ reference cross section.

In the XY cross sections, it can be seen that the different types of porosities exhibit different characteristics, which becomes even more clear, when also the $\mathrm{XZ}$ and $\mathrm{YZ}$ cross sectional views are taken into account, as shown in Figure 11. Matrix porosities are mainly large (up to $200 \mu \mathrm{m}$ in diameter), and spherical bubbles of air entrapped during the production of the IFBT test bars. Parenchyma porosities are irregular smaller porosities, in the vicinity of a technical bamboo fibre. When present in the living plant, the lumen of the parenchyma is not irregular in shape, however due to the thin wall thickness of these cells, their structure collapses during manufacturing. In longitudinal direction, the parenchyma porosities are a concatenation of block-shaped cells.

The technical bamboo fibre itself consists out of many elementary fibres which each have their own lumen. These fibre porosities are smaller than the parenchyma porosities partly due to the larger wall thickness of the cell. Fibre lumen sizes are reported between 2-20 $\mu \mathrm{m}[36,49]$. These fibre porosities run along the length of the elementary bamboo fibre which is up to $2 \mathrm{~mm}$ long [36]. Therefore, in the longitudinal cross section, the fibre porosities can be distinguished by their elongated shape.

Figure 10 gives also insight in the difference between the samples before and after hygroscopic cycling. No pronounced increase of porosities or cracks due to the hygroscopic cycling could be found. However, this does not rule out the existence of interface damage between the fibre and the matrix. In the work of Newman et al. [13] on flax/epoxy composites a $7 \%$ increase in porosity was noted after 7 hygroscopic cycles. Le Duigou et al. [56] investigated flax/PP and flax/PP+MAPP samples and a porosity content of respectively $17 \%$ and $5 \%$ was found after the $4^{\text {th }}$ hygroscopic cycle, after which the increase levelled off. Both researchers mention that pore formation was mainly observed around the fibre edges, caused by differential swelling stresses between the fibre and matrix.

Figure 12 shows the operations that were performed to distinguish between the different porosities in the $\mathrm{X}$ ray CT images. In part a) the original slice is shown. A double threshold was applied to separate all the porosities from the fibres and matrix, taking into account the pixel connectivity, resulting in Figure 12b). After 
that, the matrix porosities were eliminated based on their lower density, higher sphericity and lower surface to volume ratio, resulting in Figure 12c), which contains only the parenchyma and fibre porosities. The fibre porosities were extracted by adding a limit to the diameter of the porosities. All pores smaller than $25 \mu \mathrm{m}$ in diameter are considered as lumen, shown in Figure 12d). In this way the three porosity types were distinguished and are shown in 3D for the $\mathrm{C} 1$ reference specimen in Figure 13.

This clear separation allows to analyse the specimens with different cleanliness further, and the results are summarised in Table 5. The total porosity decreases as the fibres get more clean. Samples with the most clean fibres are more than $50 \%$ less porous. This decrease is linked to a decrease in parenchyma porosities, since this is the tissue removed when cleaning the fibres, but also to a decrease in matrix porosity. The latter is explained by considering the production process of the IFBT where no vacuum is applied. The fibres are manually impregnated, by dipping them several times in the resin and squeezing out the air. The more parenchyma that is present on the fibre surface, the rougher the surface and the higher the difficulty to remove all the air. The decrease in parenchyma porosity accounts for roughly $40 \%$ of the total porosity decrease, while the decrease in matrix porosity accounts for the remaining $10 \%$.

Fibre porosities (lumen) vary for all specimens considered between $4.2-9.6 \%$. It was checked whether the fibre porosity was linearly related to the volume fraction of the specific tensile bar from which the specimen was taken, but no correlation could be found. Performing a basic calculation, allows estimating the average lumen size in the elementary fibres. Suppose the elementary fibres have an average diameter of $30 \mu \mathrm{m}$ and the porosity ranges between $4-10 \%$, this would mean the lumen size would range between $6-10 \mu \mathrm{m}$. However as the fibres mature, additional cell wall layers will first be deposited within the fibres near the conducting tissue, and this will proceed outwards, towards the edge of the fibre bundle. The lumen of mature fibres will be smaller than those of immature fibres. This is seen in Figure 14, where an arrow indicates the maturisation direction for each technical fibre. From the picture one might estimate a bimodal distribution, with lumen sizes smaller than $6 \mu \mathrm{m}$ and other larger than $10 \mu \mathrm{m}$. Therefore the calculation seems plausible. The fibre porosity can be seen as the natural variety of the plant, independent of the cleanliness of the fibres.

For the considered samples an increase in total porosity is found comparing the reference samples and those after hygrosopic cycling. However, this may be considered a coincidence, since the specimens analysed before 
and after hygroscopic cycling do not originate from the same tensile bar sample and since the major difference in total porosity is found in the amount of parenchyma porosity, which is a priori not expected to increase with cycling. Also the fact that no cracks were visible on the cross sectional views, confirms this statement. While this might indicate that the damage accumulation is minor, it has to be pointed out that interface cracks might still be present, since those would be hard to observe at the $2 \mu \mathrm{m}$ resolution of the CT scan. Also the mechanical properties of the uncleaned samples showed a strong decrease after hygroscopic cycling, which suggest some interface damage.

\section{Conclusion}

The hygroscopic behaviour of bamboo fibre reinforced composites was studied both for static and cyclic moisture conditioning

Static conditioning revealed that bamboo fibre reinforced composite retains a higher Young's modulus in moist conditions. A drop of $25 \%$ in Young's modulus at $30{ }^{\circ} \mathrm{C}$ and $80 \% \mathrm{RH}$ was found whilst both the strength and the strain to failure increased. These results are better from what is found in flax fibre reinforced composites, where a much larger decrease in Young's modulus and in most cases a reduction in tensile strength for similar conditions is noted.

Dynamic mechanical analysis was performed on flax and bamboo fibre reinforced epoxy composites to further investigate this difference. The behaviour of wet and dry conditioned samples was assessed. Analysing the loss factor versus temperature curve, reveals that a $T_{g}$ decrease of $17{ }^{\circ} \mathrm{C}$ is found for the flax fibre reinforced composite in wet state. For the bamboo fibre reinforced composite, only a secondary transition was found below $200{ }^{\circ} \mathrm{C}$ and no difference in wet state could be observed. The explanation is found in the composition of the fibres. Since bamboo has a high lignin content, which retains a rather high $T_{g}$ in moist conditions, the overall composite $T_{g}$ stays high. Flax fibres which contain almost no lignin, depend on the behaviour of cellulose and hemicellulose and pectin in moist conditions, and therefore show a clear $T_{g}$ decrease. This was also visible in a reduced storage modulus and increased loss factor with temperature for the wet flax fibre composite. The bamboo fibre composite showed no change in any of the DMA analysed mechanical 
properties (storage and loss modulus and loss factor) in the wet state, confirming the results from the IFBT tests at high humidity.

Bamboo fibre reinforced composites were subjected to cyclic hygroscopic conditioning where the influence of the residual parenchyma on the mechanical properties was assessed. Parenchyma has a more open structure than bamboo fibres, inherent lower mechanical properties and a lower crystallinity, resulting in a higher potential for water uptake. It was shown that after 5 hygroscopic cycles, the composites with the cleanest fibres retained the highest stiffness and strength, with no change in Young's modulus and a $22 \%$ drop in the strength of the composite. The EMC of the composites, did not show an increasing trend with increasing hygroscopic cycles, so no indication of major damage accumulating during the cycles was found.

Porosity analysis showed that composites prepared with $\mathrm{C} 1$ type of fibres, containing the highest amount of parenchyma, showed the highest porosities, up to $23.7 \%$. Matrix porosities were also higher for composites with $\mathrm{C} 1$ type of fibres. The rougher surface of the fibre impedes impregnation, resulting in increased air bubble entrapment. The total amount of parenchyma porosities decreased going from the $\mathrm{C} 1$ to $\mathrm{C} 3$ grade of cleanliness. With the cleanest fibres C3 still having a parenchyma porosity of $1.1-3.6 \%$. Fibre porosities (lumen) varied between $4.2-9.6 \%$ for all specimens and are considered as the natural variation of the plant, independent of the cleanliness of the fibre and cannot be avoided.

No large porosity differences were found for the samples in dry or wet condition. This confirms that the damage accumulation is minor, though interface cracks might still be present, being below the current detection limit of the X-ray CT set-up used.

Bamboo fibres are interesting to consider when designing natural fibre composites that need to withstand moist environments. Care should be taken in extracting and cleaning the fibres, since fibres with a low amount of parenchyma will show better performance in the long term. 
a)

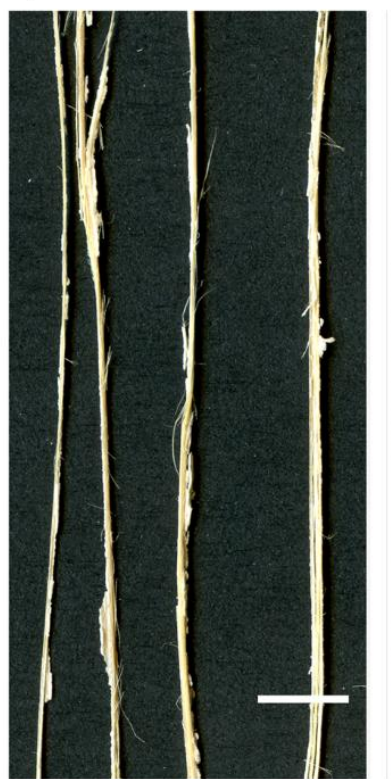

b)

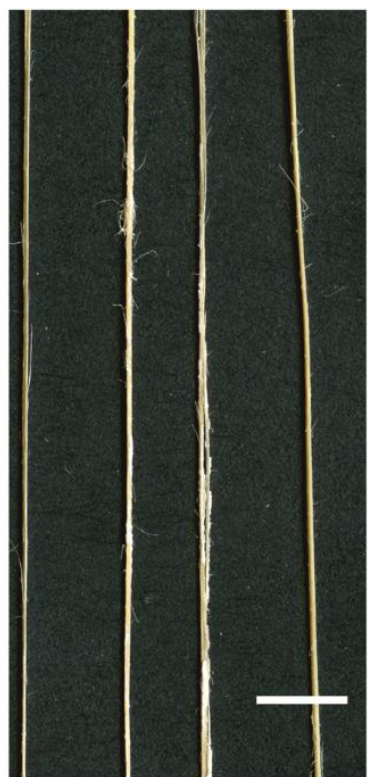

c)

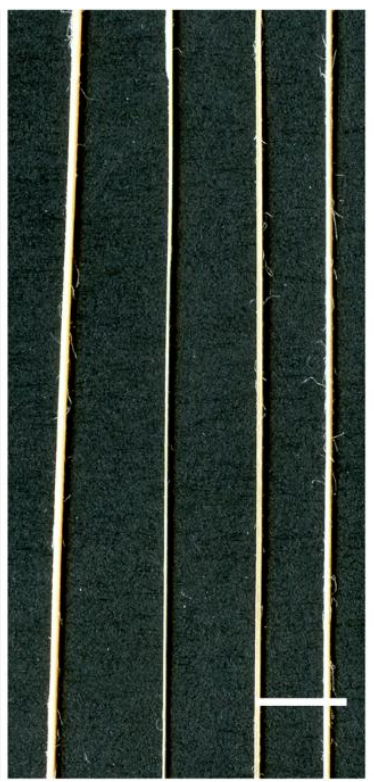

Figure 1 Section out of the scanned images of the extracted bamboo fibres with a) C1 b) C2 and c) C3 level of cleanliness, used as input for the fibre diameter characterisation. Scale bar $5 \mathrm{~mm}$

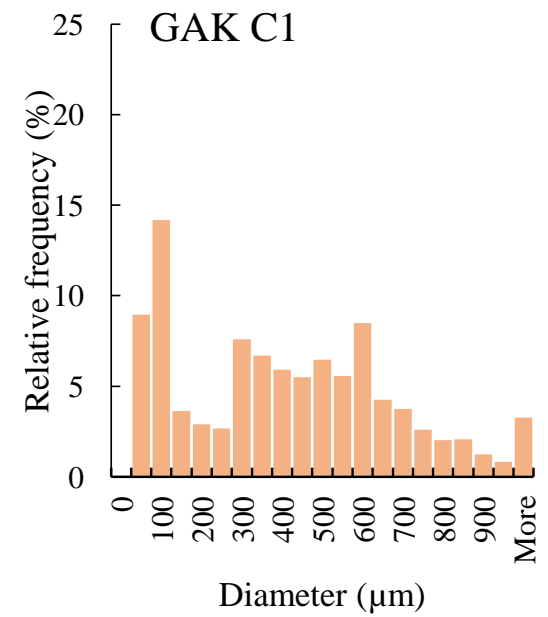

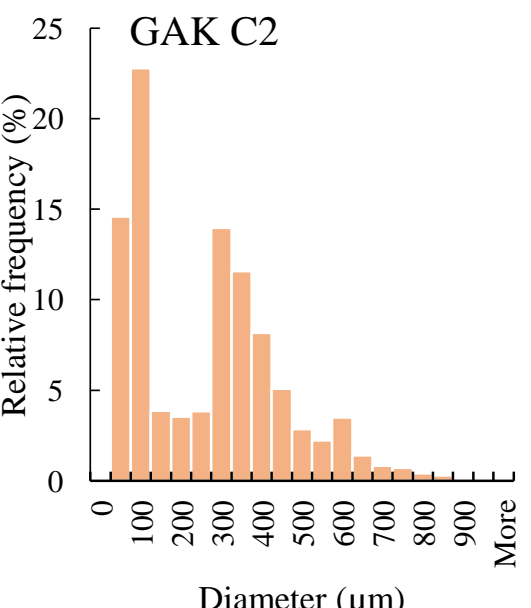

Diameter $(\mu \mathrm{m})$

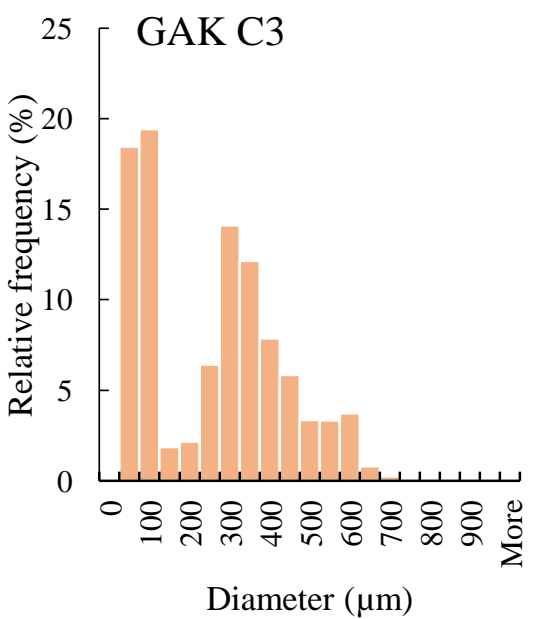

Figure 2 Diameter distribution of the different grades of cleanliness of the Guadua angustifolia Kunth bamboo fibres 

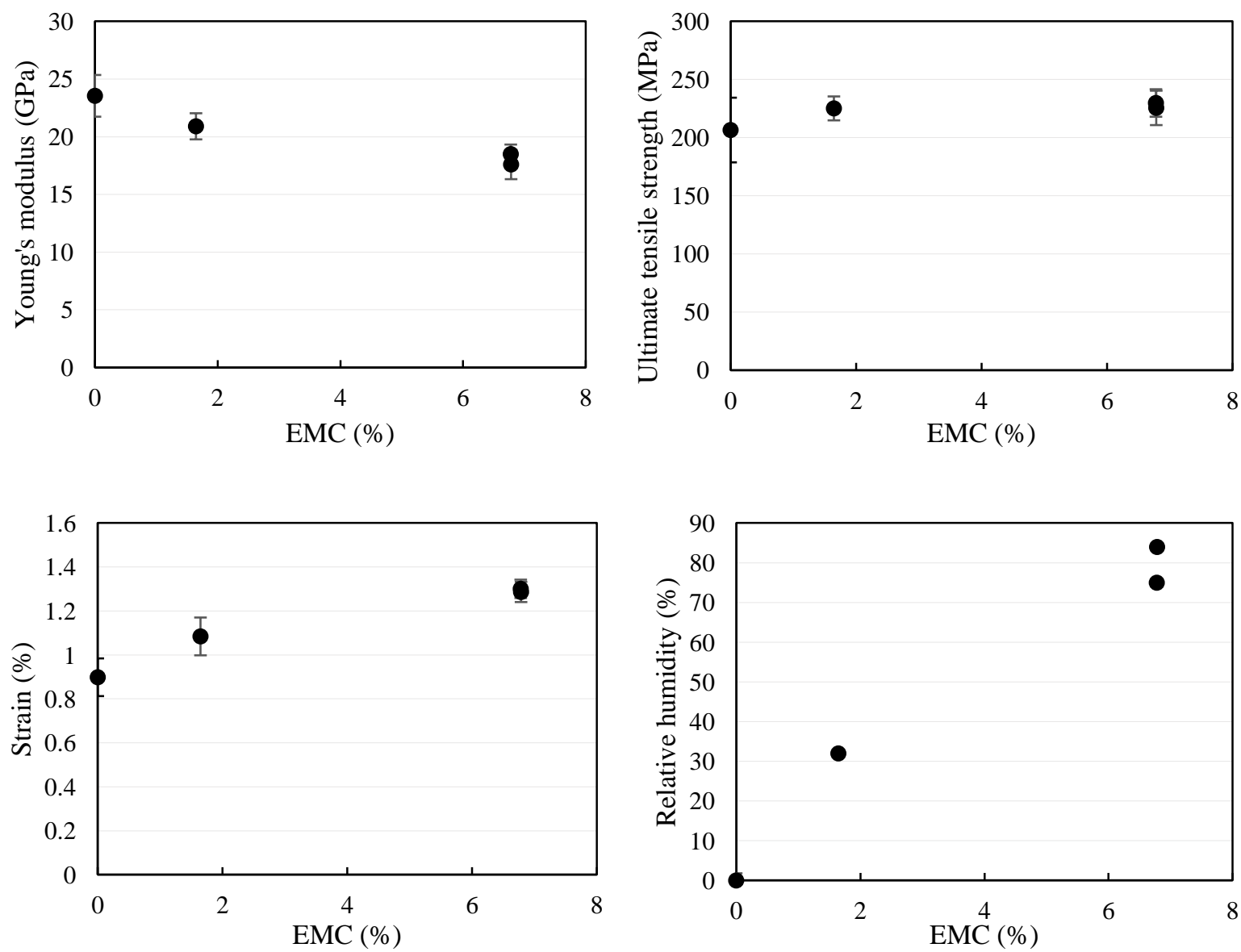

Figure 3 Overview of the mechanical properties versus the equilibrium moisture content of the conditioned bamboo/epoxy composites at $30{ }^{\circ} \mathrm{C}$ conditioned at different relative humidities: $32 \% \mathrm{RH}, 74 \% \mathrm{RH}$ and $85 \% \mathrm{RH}$ and an oven dry sample $1.2 \% \mathrm{RH}$, normalised to a fibre volume fraction of $40 \%$

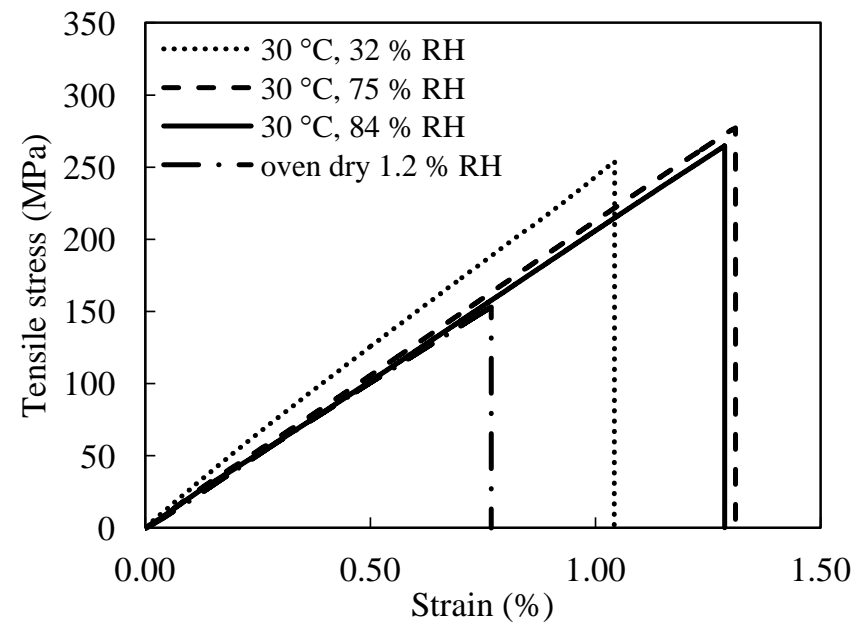

Figure 4 Typical stress-strain curve of the bamboo fibre reinforced composites conditioned at $30{ }^{\circ} \mathrm{C}$ and different relative humidities. 


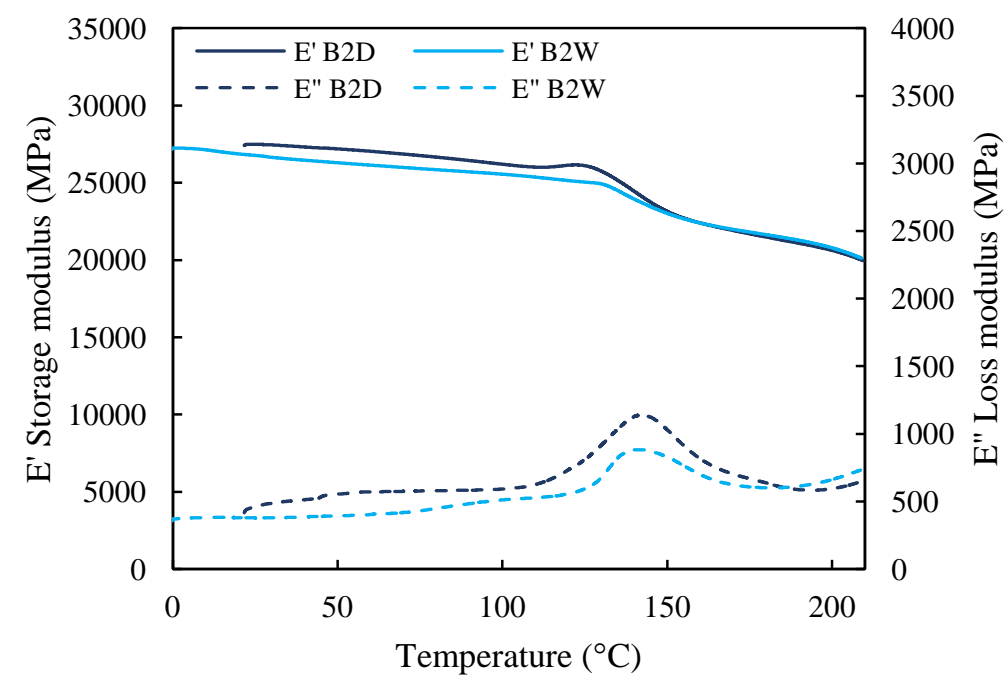

Figure 5 The evolution of the storage modulus (E') and the loss modulus (E") with temperature from the DMA experiment for a dry (D) and wet (W) conditioned bamboo (B) fibre reinforced composite

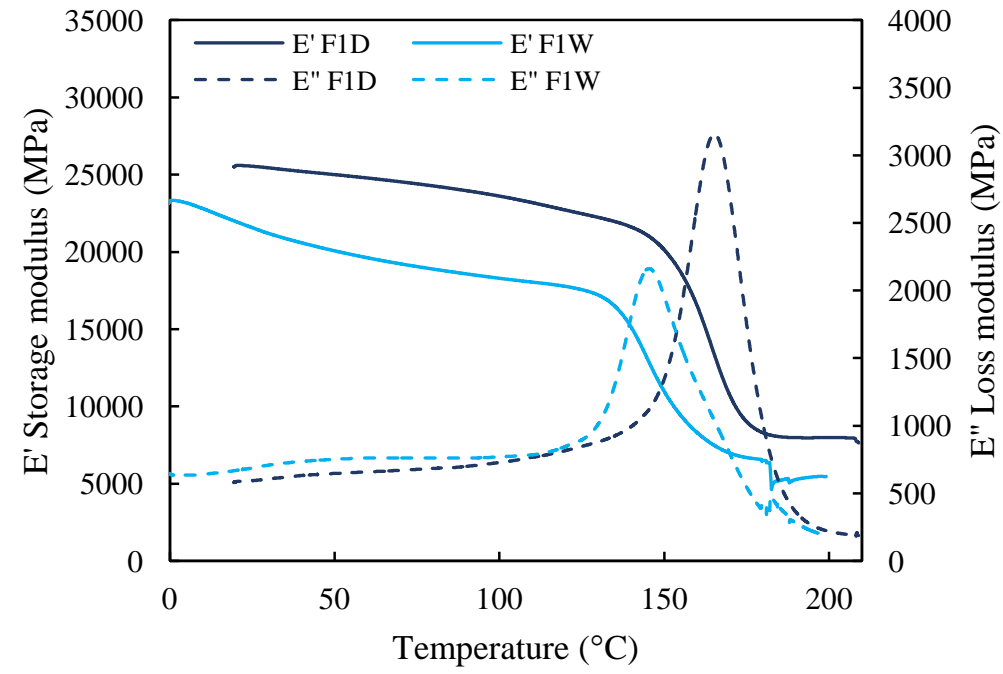

Figure 6 The evolution of the storage modulus (E') and the loss modulus (E") with temperature from the DMA experiment for a dry (D) and wet (W) conditioned flax (F) fibre reinforced composite 
a)

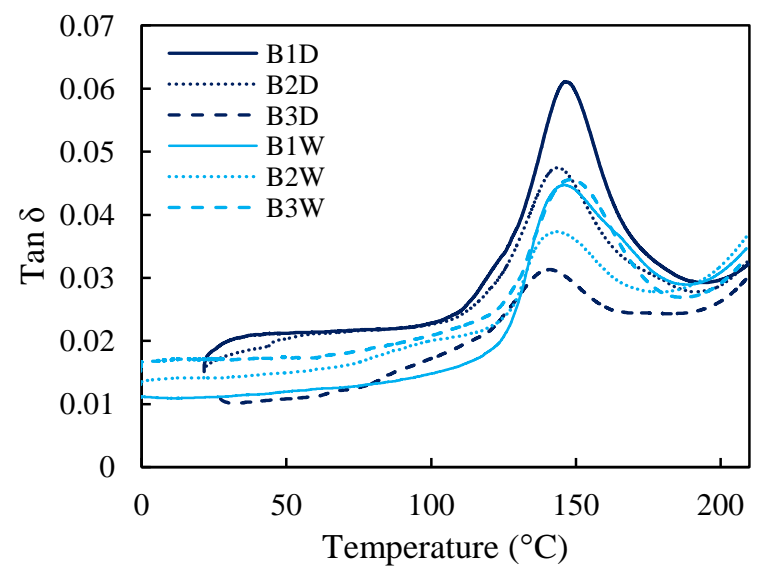

b)

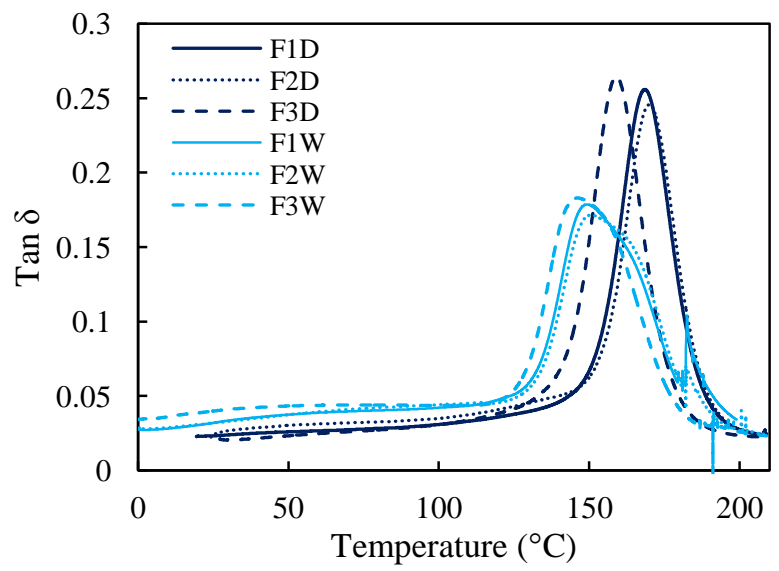

Figure 7 Loss factor (Tan $\delta$ ) versus temperature curve for the dry (D) and wet (W) a) bamboo (B) fibre reinforced composites and b) flax (F) fibre reinforced composites, three samples tested for each condition.

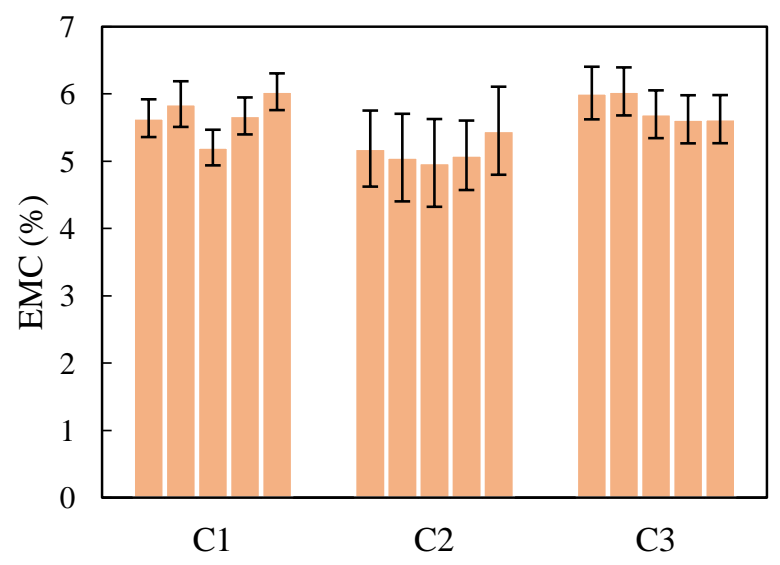

Figure 8 Equilibrium moisture content (EMC) for the composites with different cleanliness, each time 5 cycles. Hygroscopic cycling was performed between dry $\left(80{ }^{\circ} \mathrm{C} \mid 1.2 \% \mathrm{RH}\right)$ and wet $\left(80^{\circ} \mathrm{C} \mid 80 \% \mathrm{RH}\right)$ conditions. 
1

2

3

4

5

6

7

8

9

10

11

12

13

14

15

16

17

18

19

20

21

22

23

24

25

26

27

28

29

30

31

32

33

34

35

36

37

38

39

40

41

42

43

44

45

46

47

48

49

50

51

52

53

54

55

56

57

58

59

60

61

62

63

64

65
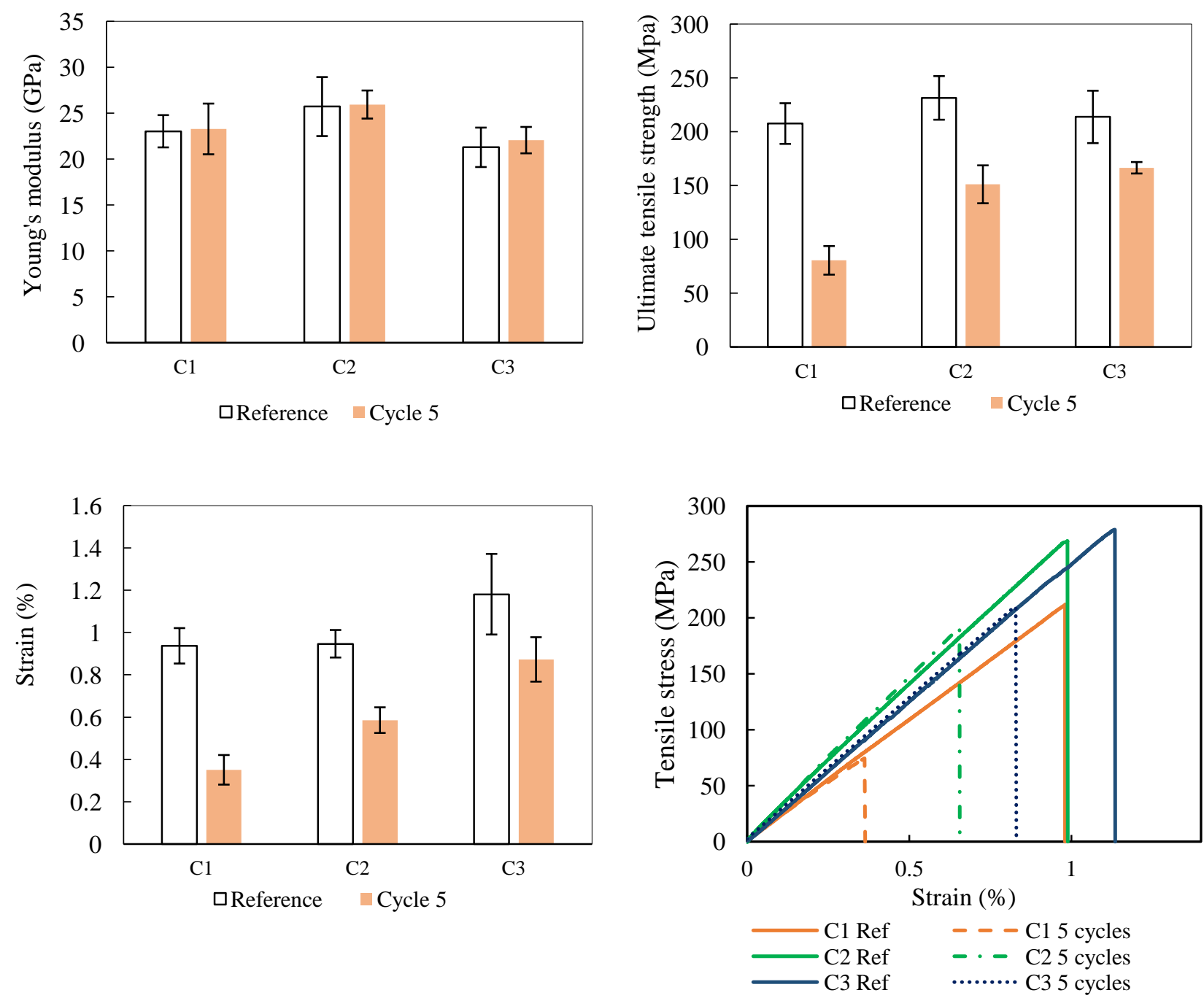

Figure 9 Mechanical properties of the cycled composites for the reference specimens (after manufacturing) and after 5 cycles, with Young's modulus and ultimate tensile strength normalised to Vf $40 \%$. A typical stress-strain curve of each of the combinations is given as well. Cycling was done at $80^{\circ} \mathrm{C}$ between $1.2 \% \mathrm{RH}$ (oven) and $80 \% \mathrm{RH}$; samples tested in fully dried state after a short reequilibration to room temperature 


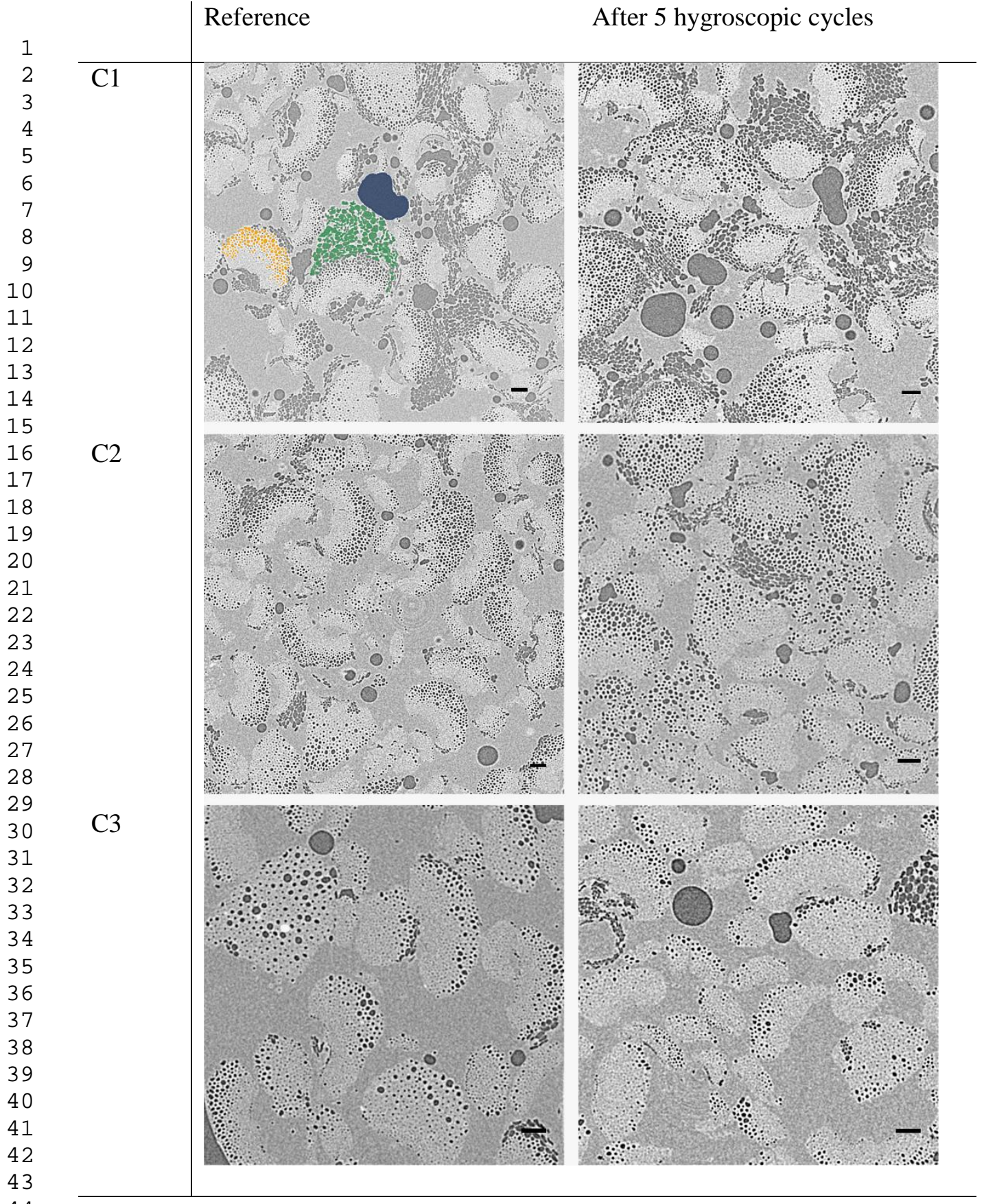

Figure 10 Cross sectional view of the composites considered obtained via X-ray CT. Each time one sample cut from a tensile test sample was scanned. A fibre porosity area is indicated in yellow, parenchyma in green and a matrix porosity in blue. Scale bar $100 \mu \mathrm{m}$ 
a)

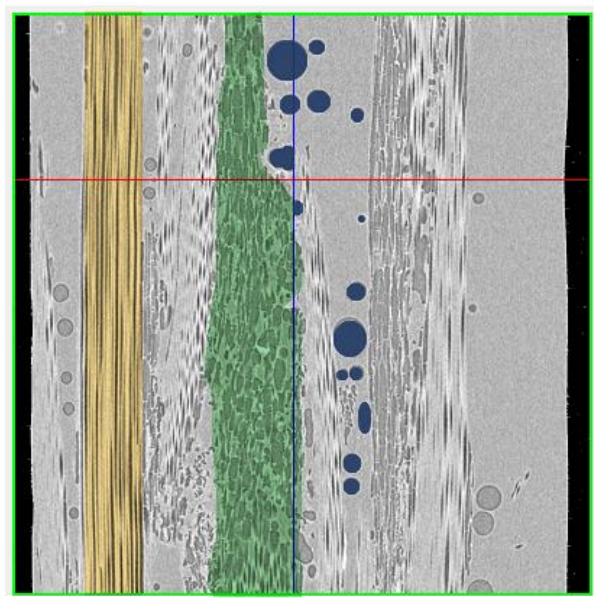

b)

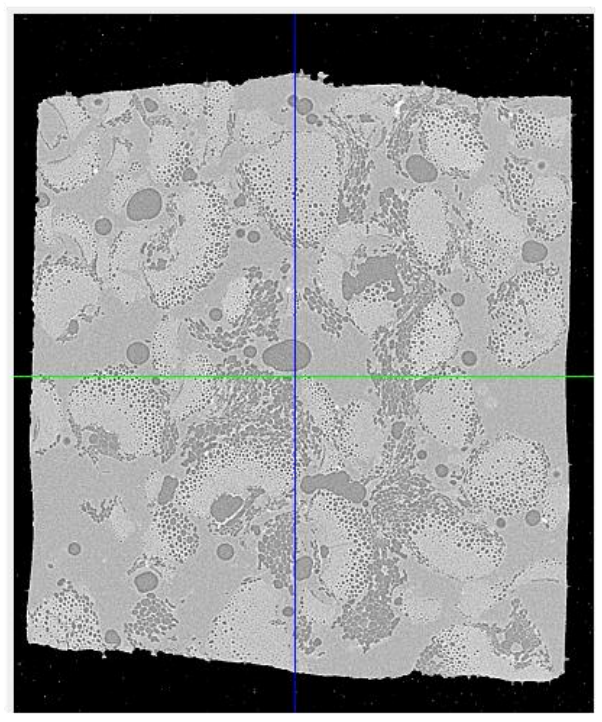

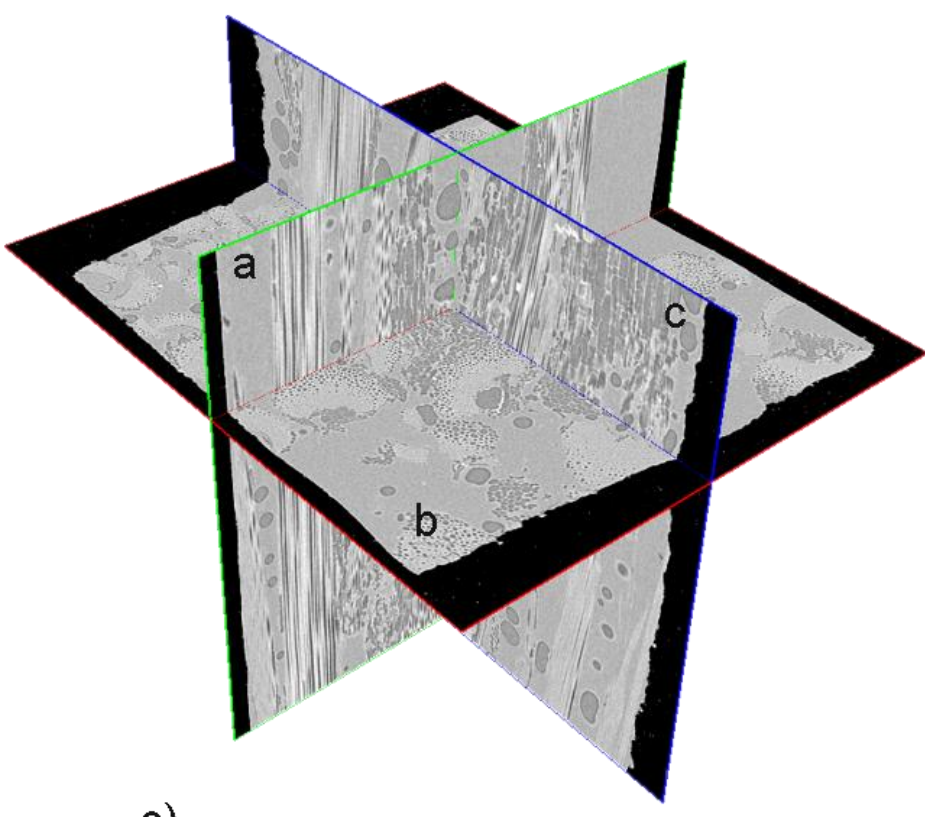

c)

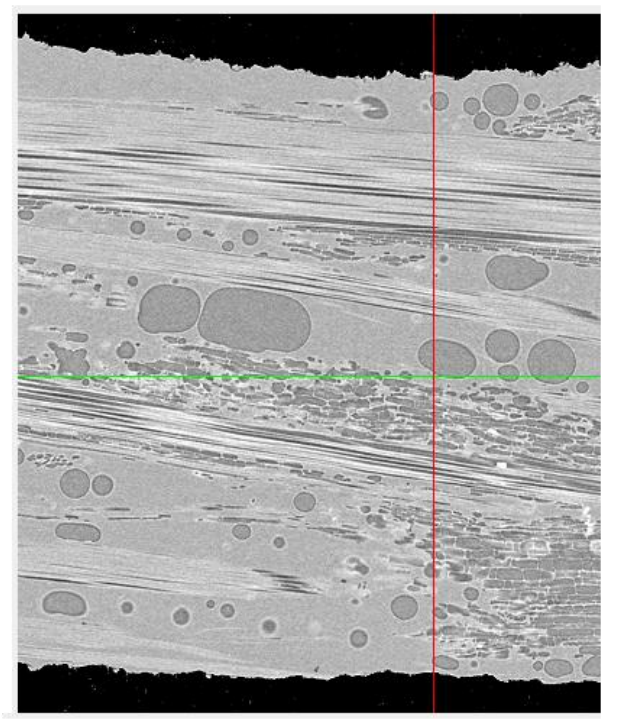

Figure 11 Different cross sectional views of a reference $\mathrm{C} 1$ sample. A fibre porosity area is indicated in yellow, parenchyma in green and some matrix porosities in blue. The corresponding cross sectional views are indicated by a), b) and c). 


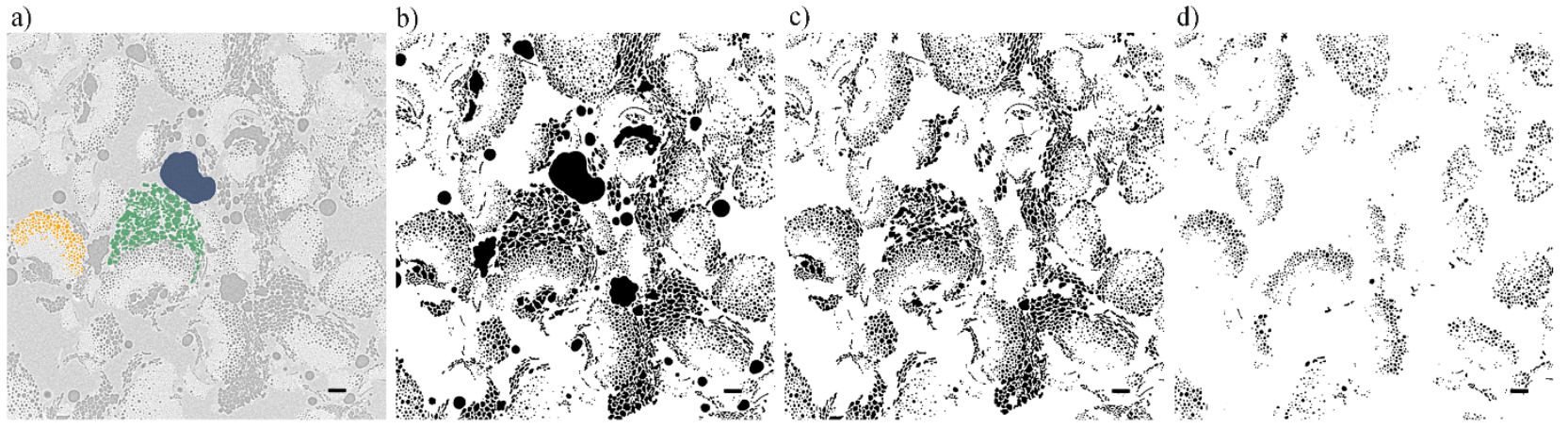

Figure 12 Illustration of the different thresholding steps to determine the different porosities for the reference $\mathrm{C} 1$ sample. a) nonthresholded sample b) all porosities in black c) parenchyma and fibre porosities in black c) only fibre porosities. Scale $100 \mu \mathrm{m}$

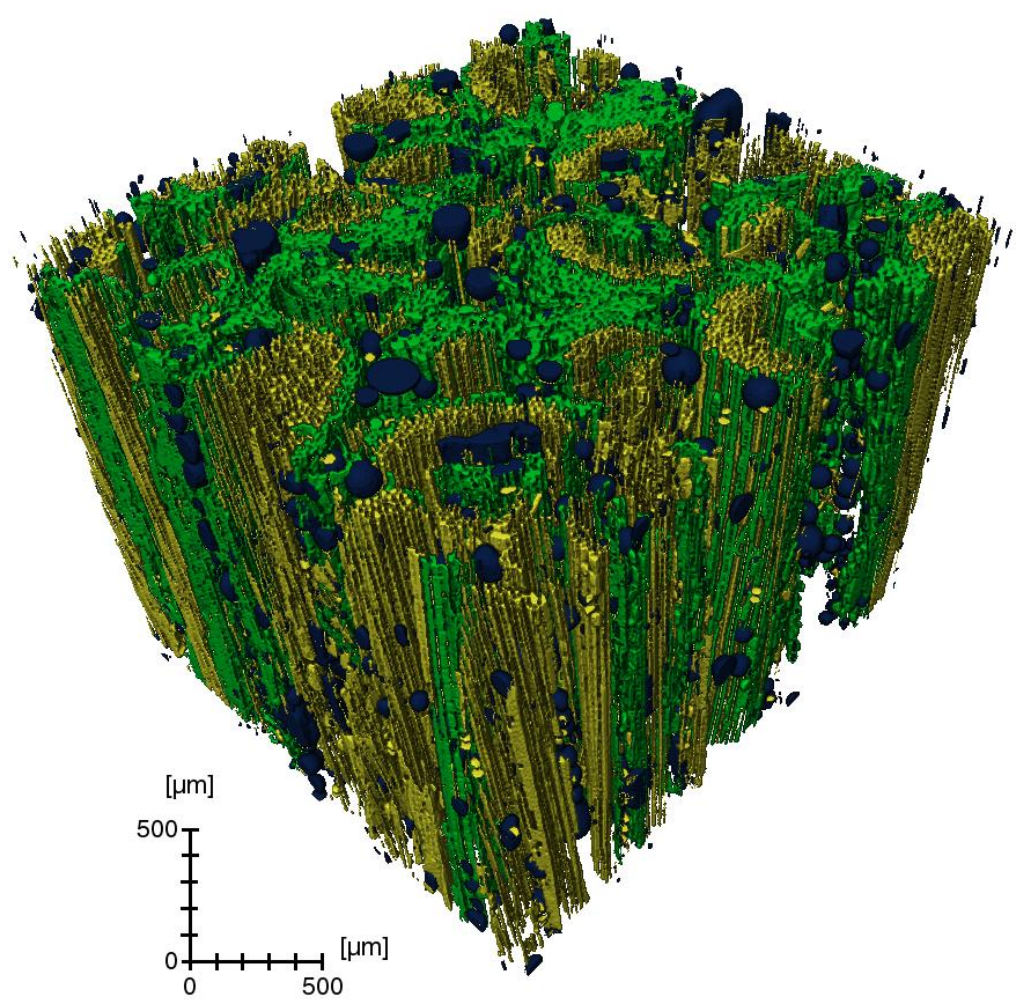

Figure 13 3D view of the different porosities present in the $\mathrm{C} 1$ reference sample. Fibre porosities in yellow, parenchyma in green and the matrix porosities in blue 


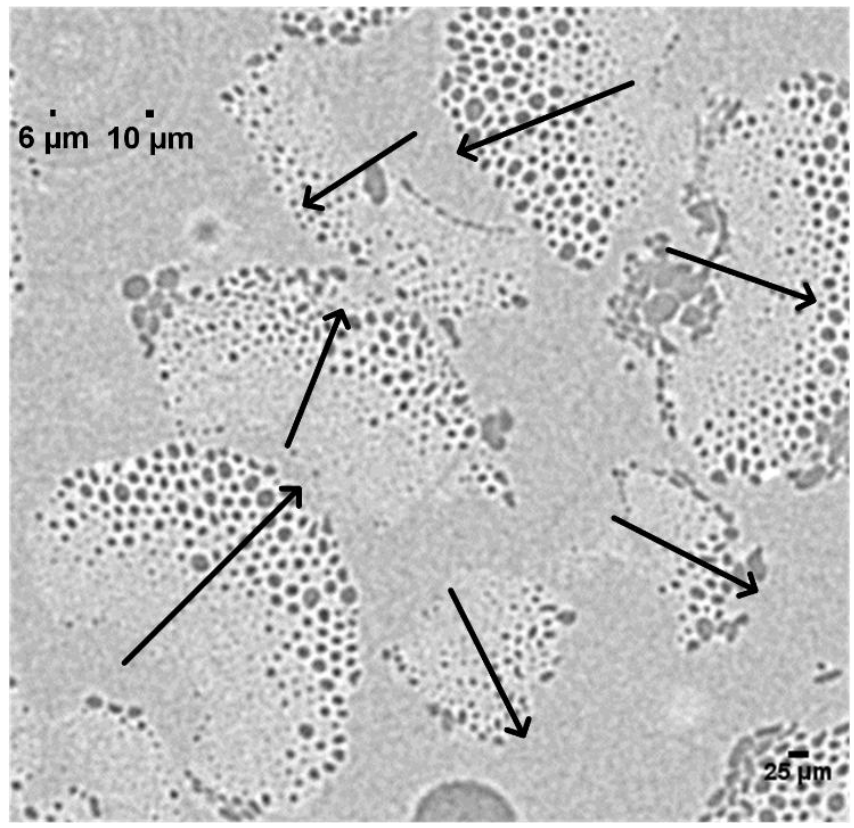

Figure 14 Zoom of the $\mathrm{C} 2$ reference $\mathrm{XY}$ cross section, the arrows indicate the maturisation direction of the elementary fibres within the fibre bundle. Calculated lumen size of $6-10 \mu \mathrm{m}$ are indicated with a scale bar and can be compared with the given morphology 
Table 1 Overview of the change in thermoset composite performance in the fibre direction, when tested in moist or wet condition, as reported in literature

\begin{tabular}{|c|c|c|c|c|c|c|c|}
\hline Fibre and architecture & Matrix & Vf\% & Conditioning & $E$ & $\sigma$ & $\varepsilon$ & Reference \\
\hline $\begin{array}{l}\text { UD glass fibre } \\
\text { UD flax fibre }\end{array}$ & $\begin{array}{l}\text { Polyester } \\
\text { Polyester }\end{array}$ & $\begin{array}{l}54 \\
32\end{array}$ & $\begin{array}{l}30{ }^{\circ} \mathrm{C} \text {, immersion in water } 30 \\
{ }^{\circ} \mathrm{C} \text {, immersion in water }\end{array}$ & $\begin{array}{l}\cong \\
\downarrow 37 \%\end{array}$ & $\begin{array}{l}\downarrow 8 \% * \\
\uparrow 34 \%\end{array}$ & $\begin{array}{l}1 \\
1\end{array}$ & {$[14]$} \\
\hline UD flax fibre & Epoxy & 44 & $\begin{array}{l}20^{\circ} \mathrm{C}, 90 \% \mathrm{RH} \\
40{ }^{\circ} \mathrm{C}, 90 \% \mathrm{RH} \\
\end{array}$ & $\begin{array}{l}\downarrow 55 \% \\
\downarrow 58 \% *\end{array}$ & $\begin{array}{l}\downarrow 12 \% \\
\downarrow 13 \% *\end{array}$ & $\begin{array}{l}\uparrow 74 \% \\
\uparrow 84 \% \\
\end{array}$ & [15] \\
\hline UD flax fibre & Epoxy & 45 & $70{ }^{\circ} \mathrm{C}, 85 \% \mathrm{RH}$ & $\downarrow 36 \%$ & $\cong$ & $\uparrow 46 \%$ & {$[18]$} \\
\hline Twill weave flax fibre & $\begin{array}{l}\text { Epoxy } \\
\text { Acrylic }\end{array}$ & $\begin{array}{l}32 \\
37 \\
\end{array}$ & $20^{\circ} \mathrm{C}$, immersion in water & $\begin{array}{l}\downarrow 57 \% * \\
\downarrow 54 \% *\end{array}$ & $\begin{array}{l}\downarrow 42 \% \\
\downarrow 42 \%\end{array}$ & $\begin{array}{l}\uparrow 100 \% \\
\uparrow 44 \% *\end{array}$ & [19] \\
\hline UD ramie & Phenolic & $\begin{array}{l}47 \\
\mathrm{wt} \%\end{array}$ & $60{ }^{\circ} \mathrm{C}, 85 \% \mathrm{RH}$ & $\downarrow 60 \% *$ & I & I & [7] \\
\hline
\end{tabular}

*these values were derived from graphs

Table 2 Back calculated bamboo fibre properties at the different setting of conditioning. Samples were re-equilibrated for a short time (no longer than 15 minutes) to room temperature, where it is assumed that the moisture content of the samples remains unchanged, due to the short exposure to room conditions before testing.

\begin{tabular}{lll}
\hline Temperature $\left({ }^{\circ} \mathrm{C}\right) \mid \mathrm{RH}(\%)$ & Young's modulus fibre & Strength fibre \\
\hline $80 \mid 1.2$ & $55 \pm 5$ & $513 \pm 69$ \\
$30 \mid 32$ & $48 \pm 3$ & $558 \pm 25$ \\
$30 \mid 74$ & $42 \pm 2$ & $569 \pm 30$ \\
$30 \mid 85$ & $40 \pm 3$ & $559 \pm 37$
\end{tabular}


Table 3 Summary of the (glass) transition temperature taken as the maximum of the tan $\delta$ curve

\begin{tabular}{lllll}
\hline & $\begin{array}{l}\text { Bamboo: secondary } \\
\text { transition }\end{array}$ & & Flax: $T_{g}$ & \\
Sample & Dry $\left(80^{\circ} \mathrm{C} \mid 1.2 \% \mathrm{RH}\right)$ & Wet $\left(80^{\circ} \mathrm{C} \mid 80 \% \mathrm{RH}\right)$ & Dry $\left(80^{\circ} \mathrm{C} \mid 1.2 \% \mathrm{RH}\right)$ & $\mathrm{Wet}\left(80^{\circ} \mathrm{C} \mid 80 \% \mathrm{RH}\right)$ \\
\hline 1 & 146 & 145 & 168 & 149 \\
2 & 143 & 143 & 170 & 151 \\
3 & 140 & 147 & 159 & 146 \\
\hline & $143 \pm 3$ & $145 \pm 2$ & $166 \pm 6$ & $149 \pm 2$
\end{tabular}

Table 4 Summary of the average bamboo composite properties for the composites with different parenchyma content for the reference samples and after 5 hygroscopic cycles, normalized to Vf $40 \%$

\begin{tabular}{llll}
\hline & Young's modulus & Strength & Strain to failure (\%) \\
\hline C1 reference & $23 \pm 2$ & $208 \pm 19$ & $0.94 \pm 0.08$ \\
C1 5 cycles & $15 \pm 5$ & $81 \pm 13$ & $0.71 \pm 0.11$ \\
C2 reference & $26 \pm 3$ & $232 \pm 20$ & $0.95 \pm 0.07$ \\
C2 5 cycles & $20 \pm 6$ & $151 \pm 18$ & $1.26 \pm 0.14$ \\
C3 reference & $21 \pm 2$ & $214 \pm 24$ & $1.18 \pm 0.19$ \\
C3 5 cycles & $22 \pm 1$ & $167 \pm 5$ & $0.87 \pm 0.11$ \\
\hline
\end{tabular}


Table 5 Overview of the porosity distribution of the bamboo composites obtained by analysing the CT scan data. Reference and after 5 hygroscopic cycles specimens were taken from different samples

\begin{tabular}{lllll}
\hline & Total porosity $(\%)$ & Matrix porosity $(\%)$ & Parenchyma porosity $(\%)$ & Fibre porosity $(\%)$ \\
\hline C1 reference & 22.6 & 5.0 & 12.5 & 5.0 \\
C1 5 cycles & 23.7 & 5.2 & 14.3 & 4.2 \\
C2 reference & 13.7 & 1.7 & 3.9 & 8.1 \\
C2 5 cycles & 16.1 & 1.7 & 4.8 & 9.6 \\
C3 reference & 8.0 & 0.7 & 1.1 & 6.2 \\
C3 5 cycles & 11.3 & 1.9 & 3.6 & 5.8 \\
\hline
\end{tabular}




\section{Acknowledgements}

The authors would like to acknowledge the support of the Impulse Fund KU Leuven (BOF/IMP14/034) and the KU Leuven C2 project (C24/17/052), regarding in situ X-ray CT characterisation of composite materials and tissues during mechanical testing.

\section{References}

[1] Faruk O, Bledzki AK, Fink HP, Sain M. Progress Report on Natural Fiber Reinforced Composites. Macromolecular Materials and Engineering. 2014;299(1):9-26.

[2] Bourmaud A, Beaugrand J, Shah DU, Placet V, Baley C. Towards the design of high-performance plant fibre composites. Progress in Materials Science. 2018;97:347-408.

[3] Pickering KL, Efendy MGA, Le TM. A review of recent developments in natural fibre composites and their mechanical performance. Composites Part a-Applied Science and Manufacturing. 2016;83:98-112.

[4] Vaisanen T, Das O, Tomppo L. A review on new bio-based constituents for natural fiber-polymer composites. Journal of Cleaner Production. 2017;149:582-96.

[5] Azwa ZN, Yousif BF, Manalo AC, Karunasena W. A review on the degradability of polymeric composites based on natural fibres. Materials \& Design. 2013;47:424-42.

[6] Perremans D, Trujillo E, Ivens J, Van Vuure AW. Effect of discontinuities in bamboo fibre reinforced epoxy composites. Composites Science and Technology. 2018;155:50-7.

[7] Le Duigou A, Davies P, Baley C. Environmental Impact Analysis of the Production of Flax Fibres to be Used as Composite Material Reinforcement. Journal of Biobased Materials and Bioenergy. 2011;5(1):153-65.

[8] Pervaiz M, Sain MM. Carbon storage potential in natural fiber composites. Resources Conservation and Recycling. 2003;39(4):325-40.

[9] Joshi SV, Drzal LT, Mohanty AK, Arora S. Are natural fiber composites environmentally superior to glass fiber reinforced composites? Composites Part a-Applied Science and Manufacturing. 2004;35(3):371-6.

[10] Tian F, Pan YH, Zhong Z. A long-term mechanical degradation model of unidirectional natural fiber reinforced composites under hydrothermal ageing. Composites Science and Technology. 2017;142:156-62.

[11] Glass SV, Zelinka SL. Moisture Relations and Physical Properties of Wood. Wood handbook - Wood as an engineering material. Madison, USA2010.

[12] Le Duigou A, Bourmaud A, Baley C. In-situ evaluation of flax fibre degradation during water ageing. Industrial Crops and Products. 2015;70:204-10.

[13] Newman RH. Auto-accelerative water damage in an epoxy composite reinforced with plain-weave flax fabric. Composites Part A: Applied Science and Manufacturing. 2009;40(10):1615-20.

[14] Dhakal HN, Zhang ZY, Richardson MOW. Effect of water absorption on the mechanical properties of hemp fibre reinforced unsaturated polyester composites. Composites Science and Technology. 2007;67(7):1674-83.

[15] Joseph PV, Rabello MS, Mattoso LHC, Joseph K, Thomas S. Environmental effects on the degradation behaviour of sisal fibre reinforced polypropylene composites. Composites Science and Technology. 2002;62(10):1357-72.

[16] Müssig J. Industrial Applications of Natural Fibres. West Sussex: John Wiley \& Sons Ltd; 2010.

[17] Stokke DD, Wu Q, han G. Introduction to Wood and Natural Fiber Composites. West Sussex, United Kingdom: John Wiley \& Sons; 2014.

[18] Rowell RM. Handbook of wood chemistry and wood composites. Boca Raton, USA: Taylor \& Francis Group; 2005.

[19] Alomayri T, Assaedi H, Shaikh FUA, Low IM. Effect of water absorption on the mechanical properties of cotton fabric-reinforced geopolymer composites. Journal of Asian Ceramic Societies. 2014;2(3):223-30.

[20] Stamboulis A, Baillie CA, Garkhail SK, van Melick HGH, Peijs T. Environmental durability of flax fibres and their composites based on polypropylene matrix. Applied Composite Materials. 2000;7(5-6):27394.

[21] Apolinario G, Ienny P, Corn S, Leger R, Bergeret A, Haudin JM. Effects of Water Ageing on the Mechanical Properties of Flax and Glass Fibre Composites: Degradation and Reversibility. In: Fangueiro R, 
Rana S, editors. Natural Fibres: Advances in Science and Technology Towards Industrial Applications. Dordrecht, The Netherlands: SpringerNature; 2016. p. 183-96.

[22] Scida D, Assarar M, Poilane C, Ayad R. Influence of hygrothermal ageing on the damage mechanisms of flax-fibre reinforced epoxy composite. Composites Part B-Engineering. 2013;48:51-8.

[23] Shmulsky R, Jones PD. Forest products \& wood science an introduction. West Sussex, UK: Wiley Blackwell; 2011.

[24] Walker JCF. Primary Wood Processing. Dordrecht, The Netherlands: Springer 2006.

[25] Berges M, Leger R, Placet V, Person V, Corn S, Gabrion X, Rousseau J, Ramasso E, Ienny P, Fontaine $\mathrm{S}$. Influence of moisture uptake on the static, cyclic and dynamic behaviour of unidirectional flax fibrereinforced epoxy laminates. Composites Part a-Applied Science and Manufacturing. 2016;88:165-77.

[26] Chilali A, Zouari W, Assarar M, Kebir H, Ayad R. Effect of water ageing on the load-unload cyclic behaviour of flax fibre-reinforced thermoplastic and thermosetting composites. Composite Structures. 2018;183:309-19.

[27] Symington MC, Banks WM, West OD, Pethrick RA. Tensile Testing of Cellulose Based Natural Fibers for Structural Composite Applications. Journal of Composite Materials. 2009;43(9):1083-108.

[28] Placet V, Cisse O, Boubakar ML. Influence of environmental relative humidity on the tensile and rotational behaviour of hemp fibres. Journal of Materials Science. 2012;47(7):3435-46.

[29] Celino A, Freour S, Jacquemin F, Casari P. The hygroscopic behavior of plant fibers: a review. Frontiers in Chemistry. 2014;2.

[30] Verheyden S. Karakterisering van vochtabsorptie van bamboe vezel composiet [Master Thesis]: KU Leuven; 2011.

[31] Osorio L, Trujillo E, van vuure AW, Lens F, Ivens J, Verheyden S, Verpoest I. Microstructural analysis and mechanical behaviour of bamboo fibres. Proc ECCM-15. Venice, Italy. 2012.

[32] ASM International. Characterization and Failure Analysis of Plastics. Hertfordshire, UK: American Technical Publishers Ltd.; 2003.

[33] Back EL, Salmen NL. Glass transitions of wood components hold implications for molding and pulping processes Tappi. 1982;65(7):107-10.

[34] Le Duigou A, Davies P, Baley C. Seawater ageing of flax/poly(lactic acid) biocomposites. Polymer Degradation and Stability. 2009;94(7):1151-62.

[35] Thwe MM, Liao K. Durability of bamboo-glass fiber reinforced polymer matrix hybrid composites. Composites Science and Technology. 2003;63(3-4):375-87.

[36] Liese W, Köhl M. Bamboo The plant and its uses: Springer International Publishing Switzerland 2015.

[37] Hu KL, Huang YH, Fei BH, Yao CL, Zhao C. Investigation of the multilayered structure and microfibril angle of different types of bamboo cell walls at the micro/nano level using a LC-PolScope imaging system. Cellulose. 2017;24(11):4611-25.

[38] Ahvenainen P, Dixon PG, Kallonen A, Suhonen H, Gibson LJ, Svedstrom K. Spatially-localized benchtop X-ray scattering reveals tissue-specific microfibril orientation in Moso bamboo. Plant Methods. 2017;13.

[39] Zhang XX, Li J, Yu Y, Wang HK. Investigating the water vapor sorption behavior of bamboo with two sorption models. Journal of Materials Science. 2018;53(11):8241-9.

[40] Trujillo E. Polymer composite materials based on bamboo fibers [PhD thesis]. Leuven: KU Leuven; 2014.

[41] Osorio L, Trujillo E, Van Vuure AW, Verpoest I. Morphological aspects and mechanical properties of single bamboo fibers and flexural characterization of bamboo/epoxy composites. Journal of Reinforced Plastics and Composites. 2011;30(5):396-408.

[42] Hendrickx K, Romian R, Goedemé T, Van Vuure A, Ivens J. Rapid and effective methods for the screening of flax fibres for composite applications. Proc International Conference on Composite Materials (ICCM). Copenhagen, Denmark. 2015;20 (1).

[43] Bensadoun F, Verpoest I, Baets J, Müssig J, Graupner N, Davies P, Gomina M, Kervoelen A, Baley C. Impregnated fibre bundle test for natural fibres used in composites. Journal of Reinforced Plastics and Composites. 2017:0731684417695461.

[44] Greenspan L. Humidity Fixed-Points of Binary Saturated Aqueous-Solutions Journal of Research of the National Bureau of Standards Section a-Physics and Chemistry. 1977;81(1):89-96.

[45] Sasov AY. Microtomography 2. examples of applications Journal of Microscopy-Oxford. 1987;147:17992. 
[46] Feldkamp LA, Davis LC, Kress JW. Practical cone-beam algorithm. Journal of the Optical Society of America a-Optics Image Science and Vision. 1984;1(6):612-9.

[47] Wevers M, Nicolaï B, Verboven P, Swennen R, Roels S, Verstrynge E, Lomov SV, Kerckhofs G, Van Meerbeek B, Mavridou A, Bergmans L, Lambrechts P, Soete J, Claes S, Claes H. Applications of CT for nondestructive testing and materials characterization. Industrial X-Ray Computed Tomography: Springer; 2018. p. 267-331.

[48] Canny J. A computational approach to edge detection. Ieee Transactions on Pattern Analysis and Machine Intelligence. 1986;8(6):679-98.

[49] Liese W. The Anatomy of Bamboo Culms: International Network for Bamboo and Rattan; 1998.

[50] Lorensen WE, Cline HE. Marching cubes: A high resolution 3D surface construction algorithm. Siggraph Comput Graph. 1987;21(4):163-9.

[51] Shah DU. Damage in biocomposites: Stiffness evolution of aligned plant fibre composites during monotonic and cyclic fatigue loading. Composites Part a-Applied Science and Manufacturing. 2016;83:160-8. [52] Perremans D, Guo Y, Baets J, van Vuure AW, Verpoest I. Improvement of the interphase strength and the moisture sensitivity of flax fibre reinforced bio-epoxies: effect of various fibre treatments. Proc ECCM-16. Seville, Spain. 2014.

[53] Perrier A, Touchard F, Chocinski-Arnault L, Mellier D. Quantitative analysis by micro-CT of damage during tensile test in a woven hemp/epoxy composite after water ageing. Composites Part a-Applied Science and Manufacturing. 2017;102:18-27.

[54] Graupner N, Fischer H, Ziegmann G, Mussig J. Improvement and analysis of fibre/matrix adhesion of regenerated cellulose fibre reinforced PP-, MAPP- and PLA-composites by the use of Eucalyptus globulus lignin. Composites Part B-Engineering. 2014;66:117-25.

[55] Le Duigou A, Requile S, Beaugrand J, Scarpa F, Castro M. Natural fibres actuators for smart bio-inspired hygromorph biocomposites. Smart Materials and Structures. 2017;26(12).

[56] Le Duigou A, Castro M. Hygromorph BioComposites: Effect of fibre content and interfacial strength on the actuation performances. Industrial Crops and Products. 2017;99:142-9. 